\title{
Snow Water Equivalent of Dry Snow Measured by Differential Interferometry
}

\author{
Silvan Leinss, Student Member, IEEE, Andreas Wiesmann, Senior Member, IEEE, \\ Juha Lemmetyinen, and Irena Hajnsek, Fellow, IEEE
}

\begin{abstract}
Large scale mapping of snow water equivalent (SWE) is a long-lasting request in many scientific and economical fields. Active and passive microwave remote sensing methods are explored, as local methods cannot be generalized due to the spatial inhomogeneity of the snow pack. Microwaves interact with snow by absorption, scattering, and refraction. For dry snow of a few meters depth and frequencies below $20 \mathrm{GHz}$, absorption and scattering in the snow volume are negligible compared with the backscattered energy from the underlying ground. The signal delay caused by refraction can be measured with differential radar interferometry, but phase wrapping errors and temporal decorrelation must be considered. We demonstrate that large $\triangle S W E$ can be accurately determined from dense time series of differential interferograms at $\mathrm{X}$ - and $\mathrm{Ku}$-band by temporal integration. Lost phase cycles are reconstructed with a two-frequency approach. Temporal decorrelation is minimized by a temporal resolution of $4 \mathrm{~h}$. A linear function between $\triangle \mathrm{SWE}$ and phase difference is derived, which deviates only a few percent from the exact solution and which depends negligibly on snow density and stratigraphy. $\triangle \mathrm{SWE}$ retrieved from observations of the SnowScat instrument (SSI) were validated against observed SWE from different reference instruments, installed at a test site near the town of Sodankylä, Finland. An accuracy below $\pm 6 \mathrm{~mm} \mathrm{SWE}$ was achieved at frequencies of 10 and $16 \mathrm{GHz}$ for up to $200 \mathrm{~mm}$ of $\Delta S W E$. An exceptionally high temporal coherence was observed for up to 30 days for dry snow, whereas for wet snow it decayed within hours.
\end{abstract}

Index Terms-Coherence loss, dielectric constant of snow, differential interferometry (D-InSAR), dry snow, microwave penetration of snow, real aperture radar, SnowScat, snow water equivalent (SWE), synthetic aperture radar (SAR).

\section{INTRODUCTION}

$\mathbf{S}$ NOW WATER EQUIVALENT (SWE) is an elementary input parameter for glacier mass balance estimates and

Manuscript received December 09, 2014; revised April 02, 2015; accepted April 21, 2015. Date of publication June 17, 2015; date of current version September 12,2015. The in situ data collection as well as data collection using SnowScat was supported by the European Space Agency activity "Technical assistance for the deployment of an X- to Ku-band scatterometer during the NoSREx-III experiment" (ESA ESTEC Contract 22671/09/NL/JA/ef) [1].

S. Leinss is with the Institute of Environmental Engineering, Swiss Federal Institute of Technology in Zurich (ETH), 8093 Zürich, Switzerland (e-mail: leinss@ifu.baug.ethz.ch).

A. Wiesmann is with GAMMA Remote Sensing AG, Gümligen CH-3073, Switzerland (e-mail: wiesmann@gamma-rs.ch).

J. Lemmetyinen is with the Finnish Meteorological Institute, 00560 Helsinki, Finland.

I. Hajnsek is with the Institute of Environmental Engineering, Swiss Federal Institute of Technology in Zurich (ETH), 8093 Zürich, Switzerland, and also with the Microwaves and Radar Institute, German Aerospace Center (DLR), Wessling 82234, Germany (e-mail: hajnsek @ifu.baug.ethz.ch).

Color versions of one or more of the figures in this paper are available online at http://ieeexplore.iee.org.

Digital Object Identifier 10.1109/JSTARS.2015.2432031 hydrological runoff models. Determination of SWE over large areas using satellite remote sensing remains challenging, and current satellite-based methodologies [2] are on par with land surface model estimates driven by atmospheric reanalysis data [3]. SWE is defined as the depth of water which would be obtained, if all ice contained in the snow pack were melted:

$$
\mathrm{SWE}=\frac{1}{\rho_{\mathrm{w}}} \int_{0}^{Z_{\mathrm{s}}} \rho_{\mathrm{s}}(z) \mathrm{d} z
$$

According to (1), SWE can be determined in situ and destructively by measuring snow depth (SD) $Z_{\mathrm{s}}$ and the depth dependent density $\rho_{\mathrm{s}}(z)$ relative to the volumetric mass density of water $\rho_{\mathrm{w}}$. The snow density, which is measured in the field by weighing a defined snow volume, is approximated by $\rho_{\mathrm{s}}(z)=\rho_{\text {ice }} \cdot f_{\mathrm{v}}(z)$, the product of the volumetric mass density $\rho_{\text {ice }}$ and the ice volume fraction $f_{\mathrm{v}}(z)$.

In situ methods to determine SWE nondestructively are often based on sensors buried below the snow pack and which measure pressure, gamma radiation, or acoustic signal delays [4]-[6].

In contrast to in situ methods, remote sensing techniques allow coverage of large areas. Not only airborne methods based on the absorption of gamma radiation [7]-[10] but also passive space-borne sensors based on the microwave emission of the snow pack [2], [11], [12] have a coarse spatial resolution on the kilometer-scale. Nevertheless, passive microwave sensors represent the current state-of-the-art of SWE retrieval methods; these sensors are applied operationally to generate daily estimates of SWE [2], [12].

For high-resolution SWE mapping, synthetic aperture radar (SAR) sensors with a resolution on the meter-scale are interesting candidates. Differential SAR interferometry (D-InSAR) has evolved into a common tool to detect small surface elevation changes over large areas with a vertical accuracy of a few millimeters [13], [14]. This accuracy is achievable by measuring the signal delay relative to the radar wavelength.

Snow also causes a signal delay that can be measured by differential interferometry. For dry snow $\left(T<0^{\circ} \mathrm{C}\right.$, no liquid water content present), the main energy is reflected at the snowground interface. However, the reflected signal is delayed by the snow volume due to its refractive index, which, in turn, depends on snow density. It has been shown in literature that the measured phase difference is proportional and very sensitive to small changes $\Delta \mathrm{SWE}$ [15]. Unfortunately, the need of at least two acquisitions separated by a temporal baseline makes D-InSAR techniques susceptible to atmospheric disturbances and loss of coherence [16], [17]. Even when the coherence is 
high enough, so that the phase difference related to snow can be analyzed, local deformations caused by soil freezing [18], atmospheric effects [19], and even just rough soil covered by a transparent dielectric layer [20] can impede a successful SWE estimation. Furthermore, the high sensitivity to SWE can cause phase wrapping problems as a $\triangle \mathrm{SWE}$ of $3.3 \mathrm{~cm}$ corresponds to a full phase cycle at C-band [15]. Despite these problems, research about successful SWE estimation has been published. Rott et al. [21] applied airborne data at L-band from October to February and retrieved SWE values matching measured SD data from weather stations in the region, using snow free corner reflectors as a phase reference. At C-band, the autumn-winter coherence was lost, but a change in SWE after snowfall could be detected, by comparing two ERS acquisitions separated by 6 days [21]. Limited by a rapid loss of coherence, D-InSAR applications for snow focus on short-term effects like detection of wind-drift patterns affecting the mass distribution of snow [22], [23]. To overcome the phase-wrapping problem, delta-k methods have been suggested [24], [25]. However, these are still affected by coherence loss due to a large temporal baseline. Having a large set of SAR acquisitions available, small baseline subset techniques (SBAS) have been developed to get a high temporal and spatial resolution for deformation monitoring [26]. For regions with a very high temporal decorrelation, like snow- or wetland-covered areas, SBAS techniques have been refined to small temporal baseline subsets (STBAS) to minimize the temporal decorrelation [27], [28]. Short-time series of retrieved $\triangle \mathrm{SWE}$ have been reported using ground-based acquisitions at C-band with a temporal baseline of $14 \mathrm{~min}$ [29].

In this paper, we present a method to derive $\triangle \mathrm{SWE}$ over entire winter seasons from dense time series of coherent radar acquisitions. The method is based on differential interferometry which applies to both real aperture and synthetic aperture radar systems. A two frequency approach is used to reconstruct lost phase cycles from phase-wrapping. Decorrelation is minimized by a fast sampling interval of the used radar acquisitions. The presented method is insensitive to short-term phase fluctuations, as these are removed by integrating the phase difference over time. We show that the integrated phase difference depends almost linearly on $\triangle \mathrm{SWE}$ and is almost independent on snow density and stratigraphy. Thanks to the linear dependence, the integrated phase difference can be accurately inverted to obtain $\triangle \mathrm{SWE}$. The proposed method is demonstrated and validated by measurements of the SnowScat instrument (SSI), a terrestrial real aperture radar system. Time series $\Delta \mathrm{SWE}(t)$ determined over four winter seasons were validated against observed SWE from different reference instruments on the ground.

\section{INSTRUMENT AND EXPERIMENT}

The method to integrate differential interferograms, as described later in this paper, was applied on radar acquisitions collected by the SSI. The data were acquired at a test site near the town of Sodankylä in northern Finland between October 2009 and May 2013. The SSI was developed and built to analyze the backscatter response of snow within the ESA ESTEC project KuScat Contract no. 42000 20716/07/NL/EL. Results obtained from the SSI were validated with field measurements,

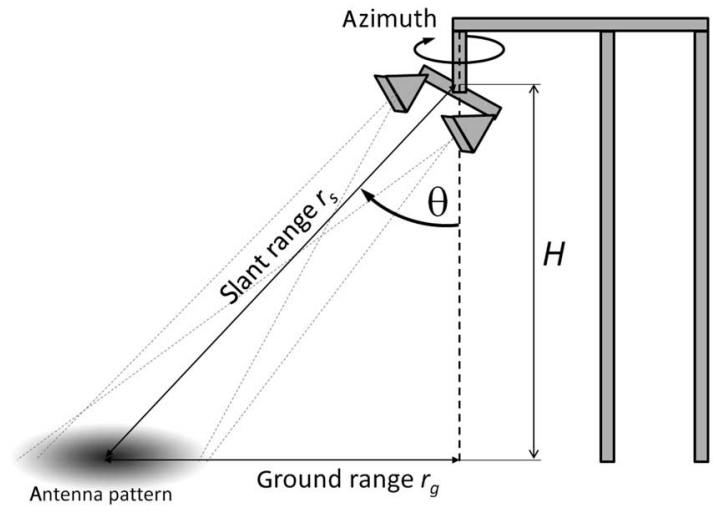

Fig. 1. The SSI with two horn antennas can rotate around the vertical axis (azimuth) and can illuminate different elevation angles $\theta$.

TABLE I

TECHNICAL SPECIFICATIONS OF THE SSI

\begin{tabular}{|l|l|}
\hline Frequency range & $9.2-17.8 \mathrm{GHz}$ \\
Polarizations & Quad pol (switched mechanically) \\
Band width & $8.6 \mathrm{GHz}$ \\
Frequency resolution & $3.072 \mathrm{MHz}$ \\
Slant range resolution & $3 \mathrm{~cm}$ (full bw + hamming window) \\
& $15 \mathrm{~cm}(2 \mathrm{GHz}$ hamming window) \\
Slant range pixel spacing & $17.4 \mathrm{~mm}$ \\
Antenna height $\mathrm{H}$ & $9.6 \mathrm{~m}$ above ground \\
Incidence angle $\theta$ & Used: $30^{\circ} \ldots 60^{\circ}\left(\right.$ max: $\left.-40^{\circ} \ldots 110^{\circ}\right)$ \\
Azimuth angle $a z$ & $-180^{\circ} \ldots 180^{\circ}$ \\
Temperature range & $-40^{\circ} \mathrm{C} \ldots+40^{\circ} \mathrm{C}$ (stabilized to $\left.+25^{\circ} \mathrm{C}\right)$ \\
Antenna footprint & $1.5 \mathrm{~m}$ at $\theta=30^{\circ}, 13.5 \mathrm{GHz}$ \\
(FWHM, $-3 \mathrm{~dB})$ & $5 \mathrm{~m}$ at $\theta=60^{\circ}, 13.5 \mathrm{GHz}$ \\
Azimuth beam width & $10.7^{\circ}(\mathrm{VV}), 7.7^{\circ}(\mathrm{HH})$ at $10.2 \mathrm{GHz}$ \\
(FWHM, $-3 \mathrm{~dB}$ ) & $6.7^{\circ}(\mathrm{VV}), 5.2^{\circ}(\mathrm{HH})$ at $16.8 \mathrm{GHz}$ \\
Elevation beam width & $7.7^{\circ}(\mathrm{VV}), 10.7^{\circ}(\mathrm{HH})$ at $10.2 \mathrm{GHz}$ \\
(FWHM, $-3 \mathrm{~dB})$ & $5.2^{\circ}(\mathrm{VV}), 6.7^{\circ}(\mathrm{HH})$ at $16.8 \mathrm{GHz}$ \\
\hline
\end{tabular}

supported by the Nordic Snow Radar Experiment (NoSREx), ESA ESTEC contract 22671/09/NL/JA/ef which formed a part of phase-A studies for the $\mathrm{CoReH}_{2} \mathrm{O}$ mission [30].

\section{A. SnowScat: Instrument Description and Experimental Setup}

The SSI was manufactured as a fully polarimetric, coherent, continuous-wave stepped-frequency radar by the GAMMA Remote Sensing AG [31], [32]. Mounted on a 9-m high tower, the system can rotate around a vertical axis (azimuth) and can change the elevation angle $\theta$ (schematically shown in Fig. 1). Technical specifications of the instrument are given in Table I. The instrument calibration, done once per campaign, consisted of the instrument characterization in an anechoic chamber and an additional characterization in the field. A calibration loop, made of an attenuator which connects the antenna feeding cables, is used to correct for internal system drifts and gain variations. A metallic sphere with a diameter of $25 \mathrm{~cm}$ was used as an external reference target to verify the instrument performance during the whole time of the experiment. A second reference target, a metallic plate, was used from October 2011 until June 2013. During the acquisition period of 4 years, the exact antenna position was changed by a few $\mathrm{mm}$ due to system maintenance. 


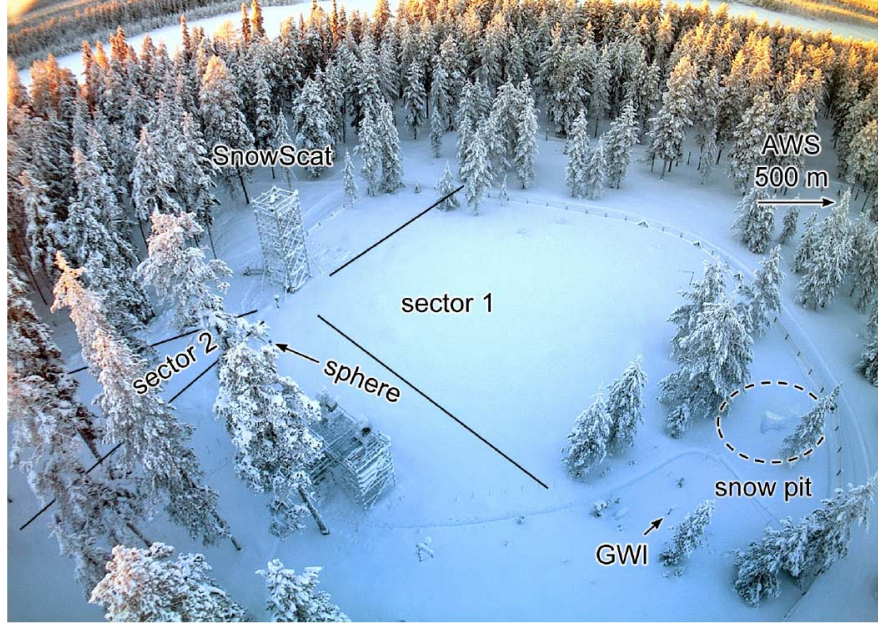

Fig. 2. The SSI was mounted on a 9-m high tower and scanned the two sectors every $4 \mathrm{~h}$. The reference target (sphere) can be located behind a tree; the other reference target (metallic plate) is hidden behind the trees close to sector 2 . The GWI and the snow pit are located about $10 \mathrm{~m}$ from sector 1 . The AWS is located $500 \mathrm{~m}$ north of the test site. Some passive microwave sensors are located on a lower tower next to the sphere.

\section{B. Data Acquisitions and Test Site Description}

A measurement sequence was run every $4 \mathrm{~h}$ autonomously by the SSI based on a preprogrammed acquisition schedule. One measurement sequence started with an acquisition of the reference target (sphere), then a scan of both sectors of the test site with different azimuth and elevation angles and ended with another acquisition of the reference target. Both sectors are shown in Fig. 2 together with the position of the reference sphere.

As shown in Fig. 3, the two sectors were divided into subsectors of $6^{\circ}$ according to the beam width of the instrument. Each subsector was measured with four different elevation angles $\theta$ from $30^{\circ}$ to $60^{\circ}$. All data were acquired in full polarization mode (HH, VV, VH, HV).

The backscatter signal, averaged over all available acquisitions during the dry snow period of winter 2012/2013, is shown in Fig. 3(left) as a polar plot. Some subsectors of sector 2 $\left(\theta=40^{\circ} \ldots 60^{\circ}\right.$ for $\mathrm{az}=-142^{\circ} \ldots-148^{\circ}$ as well as $\left.-166^{\circ}\right)$ were disturbed by trees, especially at lower frequencies where the beam width was larger. These subsectors were excluded from the analysis. The trees are also visible in the shaded relief obtained from terrestrial three-dimensional (3-D)-laser scans [Fig. 3(right)].

Both sectors of the test site contain mineral soil covered by low lichen, moss, heather, and some tree stumps. During the whole time of the experiment, sector 1, the "soil sector," remained in its natural state. On 23-08-2011, sector 2 was smoothed, filled with sand, and covered by a metallic mesh. The mesh shielded the underlying soil to isolate purely snow-specific effects.

\section{Meteorological Instruments}

Several meteorological instruments were installed at the test site (Fig. 2). An automatic weather station (AWS), located

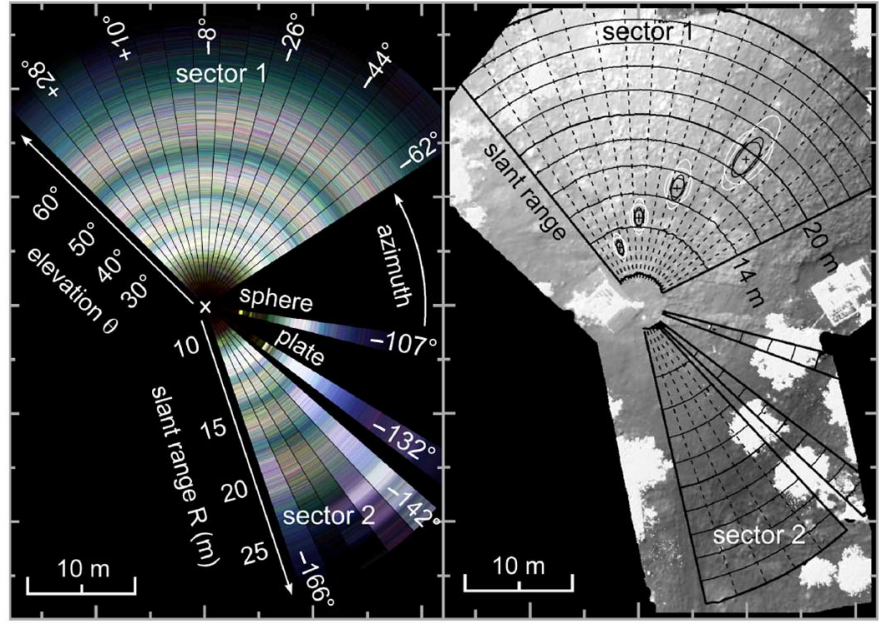

Fig. 3. Left: average backscatter signal for the winter $2012-2013$ at $13.5 \mathrm{GHz}$ $(b w=4.4 \mathrm{GHz})$ shown in the Lexicographic representation $[\mathrm{RGB}=(\mathrm{HH}, \mathrm{XX}$, $\mathrm{VV})$ ]. Both sectors were scanned with four different elevation angles $\theta$. For each $\theta$, the antenna pattern appears as a concentric circle. The sectors are defined by their azimuth-angles. The reference targets are visible at az $=-107^{\circ}$ (sphere) and $\mathrm{az}=-132^{\circ}$ (plate) as white dots at near range $(10.2$ and $11.8 \mathrm{~m})$. Sector 2 shows some backscattering from trees $\left(\mathrm{az}=-142^{\circ},-148^{\circ}\right.$, and $\left.-166^{\circ}\right)$. Right: shaded relief computed from terrestrial laser scanner data $(08-$ 10-2010). The left site of sector 1 is about $1 \mathrm{~m}$ higher than sector 2 . The grid indicates the range and azimuth coordinate system of the instrument. Ellipses show the $-3 \mathrm{~dB}$ antenna footprints at $9.2 \mathrm{GHz}$ (white) and $17.8 \mathrm{GHz}$ (black).

$500 \mathrm{~m}$ north of the SSI, measured SD, air temperature, wind speed, precipitation, and other meteorological parameters once per minute. In a snow pit near the instrument, SWE and snow density were measured manually at least once per week. The gamma water instrument (GWI), an experimental instrument to measure SWE, was located close to the snow pit about $10 \mathrm{~m}$ from sector 1. The GWI determined SWE by absorption of gamma radiation in the snow pack from a radiation source below the snow cover. Daily mean values were calculated to obtain statistically significant results from the gamma counts. The daily mean values were calibrated with manual SWE measurements from the snow pit. Additionally to the GWI, SWE was also determined from the accumulated precipitation measured by the AWS. Owing to the spatial distance between both instruments, the AWS data showed some systematic deviation from the GWI data. SWE derived from the SSI was in best accordance with SWE measured by the AWS and GWI, when the data of both instruments were combined into a synthetic reference (for details, see Section VI-A).

\section{SnowScat as an Interferometer}

The SSI was developed with the primary purpose to analyze backscatter properties of snow. However, in this section we demonstrate that the instrument, which was constructed as a coherently operating radar, can also be used for interferometric measurements. The long-term phase drifts and daily phase fluctuations are small enough to keep the measurement error of SWE well below $6 \mathrm{~mm}$ as shown below.

To determine the phase stability of the system, the range variations $\Delta r=R(t)-R_{\text {ref }}$ between the reference sphere and 


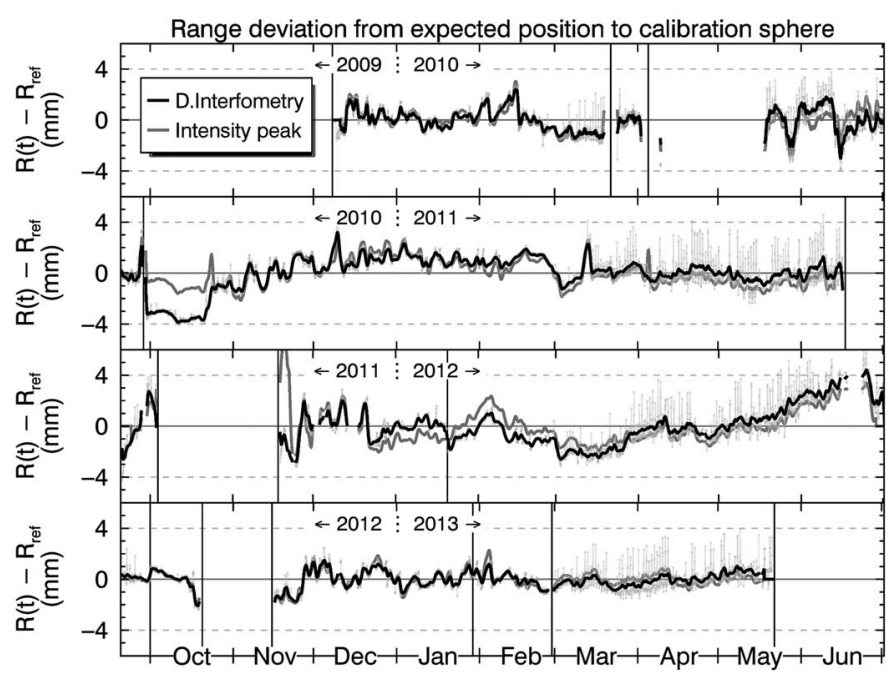

Fig. 4. Range variations $R(t)-R_{\text {ref }}$ between the SSI and the reference target (sphere) measured by differential interferometry (black line) and by identifying the peak in the backscatter signal of the sphere (gray line). Both lines show daily averages. Vertical lines separate measurement periods between maintenance events (e.g., remounting the instrument). $R_{\text {ref }}$ for each period is given in Table II. The raw data from individual interferometric measurements (thin gray lines in the background) show daily variations during spring season.

TABLE II

Reference Distance $R_{\text {Ref }}$ Between the Sphere and the SSI

\begin{tabular}{|c|ccc|}
\hline Measurement period & $R_{\text {ref }}(\mathrm{cm})$ & RMSE (mm) & max err.(mm) \\
\hline 29-10-2009 to $19-03-2010$ & 1006.7 & 0.8 & 2.4 \\
$19-03-2010$ to $02-07-2010$ & 1005.1 & 1.1 & 3.0 \\
$28-09-2010$ to $16-06-2011$ & 1015.0 & 1.4 & 3.9 \\
$18-11-2011$ to $19-01-2012$ & 1023.6 & 1.0 & 2.8 \\
$19-01-2012$ to $18-06-2012$ & 1024.3 & 1.6 & 4.4 \\
$27-09-2012$ to $19-10-2012$ & 1024.6 & 0.9 & 3.3 \\
$16-11-2012$ to $30-01-2013$ & 1024.2 & 0.8 & 1.8 \\
$30-01-2013$ to $28-02-2013$ & 1023.1 & 0.6 & 2.6 \\
$28-02-2013$ to $21-05-2013$ & 1022.7 & 0.5 & 1.6 \\
\hline
\end{tabular}

The root-mean-square error (RMSE) and maximum error for $\left|R(t)-R_{\text {ref }}\right|$ are listed.

the instrument were analyzed by differential interferometry. A fixed reference distance $R_{\text {ref }}$ measured from the instrument to the sphere was defined for each measurement period, defined as the time between two maintenance events. During maintenance, $R_{\text {ref }}$ changed by a few millimeter to centimeter (Table II), when the instrument was remounted or cleared from snow. Between two maintenance events, the range to the sphere $R(t)$ deviated less than $\Delta R=5 \mathrm{~mm}$ from $R_{\text {ref }}$ (Fig. 4, black line. Tabel II shows numerical results).

A range displacement $\Delta r$ causes an error in SWE estimation. To estimate this error, the following formulation is provided: a refractive medium with permittivity $\epsilon$ and thickness $\Delta z$ would increase the optical path length by $\Delta r=\Delta z(\sqrt{\epsilon}-1)$. For snow, with a homogeneous density, this term can be rewritten using (1) as

$$
\Delta r=\Delta \mathrm{SWE} \cdot \frac{\rho_{\mathrm{w}}}{\rho_{\mathrm{s}}}(\sqrt{\epsilon}-1)
$$

where the factor $\rho_{\mathrm{w}} / \rho_{\mathrm{s}} \cdot(\sqrt{\epsilon}-1)$ can by approximated by $0.82 \pm 0.04$ [see (3)]. Consequently, a range uncertainty $\Delta r$ of $5 \mathrm{~mm}$ would correspond to an uncertainty of $\triangle \mathrm{SWE}=$ $\Delta r / 0.82 \approx 6 \mathrm{~mm}$.

The range-variations derived from differential interferometry were also compared with range-variations, determined by analyzing the backscatter signal. Thanks to the large bandwidth of the system $(b w=8.6 \mathrm{GHz})$, it was possible to focus the signal with a range-resolution of $17 \mathrm{~mm}$. At this resolution, the peak position in the backscatter signal of the sphere was determined with subpixel accuracy. The results differ from the results obtained by differential interferometry less than $1.5 \mathrm{~mm}$ (black vs. gray line in Fig. 4). From the difference of $1.5 \mathrm{~mm}$ between the interferometric and the backscatter analysis, we conclude a long-term phase stability less than $1.5 \mathrm{~mm} /(2 \lambda) \approx 12^{\circ}$ (using the central frequency of $13.5 \mathrm{GHz}$ ). The short-term drifts of $\pm 5 \mathrm{~mm}$ are attributed to movements of both the instrument tower and the mast of the reference sphere.

Between March and September, the distance to the reference target showed daily variations of 3-4 mm (gray vertical lines in the background of Fig. 4). The distance to the target was typically a few millimeter larger in the morning hours. The same variations were also observed for the secondary reference target, the metallic plate (data not shown). The daily variations appear when air temperatures are close to or above the temperature of the heat sink. As the daily variations are periodic, they do not affect the long-term stability of the phase and do, therefore, not affect the accuracy of SWE estimation.

\section{Physical Properties of SnOW}

\section{A. Microwave Interaction With Snow}

The relevant processes of snow-microwave interaction depend on both the macroscopic snow permittivity and the internal snow structures larger than a few millimeters. The macroscopic, relative permittivity $\varepsilon=\epsilon-j \epsilon^{\prime \prime}$ is determined by subwavelength structures of the snow volume. Dry snow can be described as a mixture of ice and air, whereas wet snow contains additionally a certain fraction of liquid water [37].

The real part $\epsilon$ determines the signal delay for dry snow and is composed of the permittivities of ice and air. Both permittivities have almost no frequency dependence between $10 \mathrm{MHz}$ and $100 \mathrm{GHz}$ [38]-[41]. In this range, $\epsilon$ depends only, slightly nonlinearly, on snow density $\rho_{\mathrm{s}}$ [Fig. 5(left)] and can be expressed [42] as

$$
\epsilon\left(\rho_{\mathrm{s}}\right)= \begin{cases}1+a_{1} \rho_{\mathrm{s}}+a_{3} \rho_{\mathrm{s}}^{3} & \rho_{\mathrm{s}} \leq 0.4 \mathrm{~g} / \mathrm{cm}^{3} \\ {\left[\left(1-\frac{\rho_{\mathrm{s}}}{\rho_{\mathrm{ice}}}\right) \epsilon_{\mathrm{h}}^{1 / 3}+\frac{\rho_{\mathrm{s}}}{\rho_{\mathrm{ice}}} \epsilon_{\mathrm{s}}^{1 / 3}\right]^{3}} & \rho_{\mathrm{s}}>0.4 \mathrm{~g} / \mathrm{cm}^{3}\end{cases}
$$

The constants are given by $\mathrm{a}_{1}=1.5995 \mathrm{~cm}^{3} / \mathrm{g}, \mathrm{a}_{3}=$ $1.861 \mathrm{~cm}^{9} / \mathrm{g}^{3}, \quad \rho_{\text {ice }}=0.917 \mathrm{~g} / \mathrm{cm}^{3}, \epsilon_{\mathrm{h}}=1.005$, and $\epsilon_{\text {ice }}=$ 3.179 (adapted from [43]).

The imaginary part $\epsilon^{\prime \prime}$ determines the penetration depth and specifies if snow appears transparent, absorbing or just as a reflecting surface. In an absorbing medium, the penetration depth $\delta$ is defined by Beer-Lambert's law $I(x)=I_{0} e^{-x / \delta}$, which describes the decay of intensity $I$ with propagation distance $x$. For wet snow, the absorption is very sensitive to the liquid water content $m_{v}$ [42], so that $\delta$ decreases to $3 \mathrm{~m}$ for 

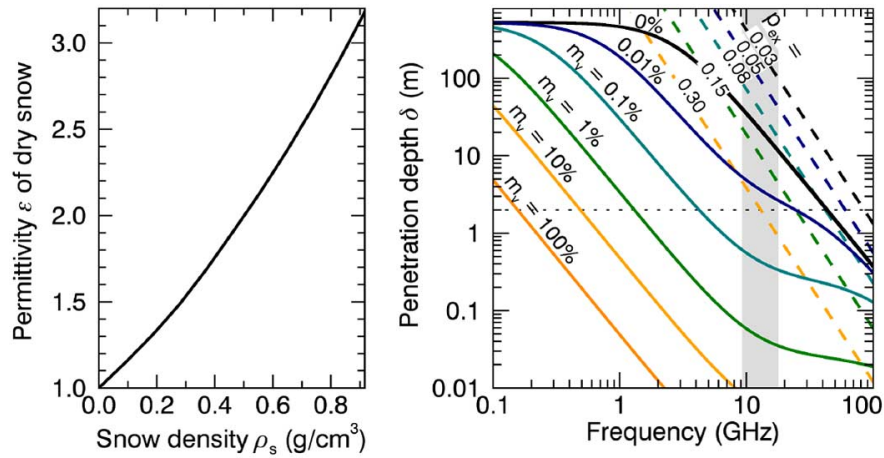

Fig. 5. Left: real part of permittivity $\epsilon$ versus snow density $\rho_{\mathrm{s}}$. Right: frequencydependence of penetration depth $\delta$ at $\rho_{\mathrm{s}}=0.3 \mathrm{~g} / \mathrm{cm}^{3}$ for different volumetric water contents $m_{v}$ (solid lines) and grain sizes (dashed) defined by the exponential correlation coefficient $p_{\mathrm{ex}}(\mathrm{mm})$. The optical grain diameter $D_{0}$ is about an order of magnitude larger: $p_{\mathrm{ex}} \approx 0.16 \ldots 0.4 D_{0}[44]$. The dotted line indicates a penetration depth of $2 \mathrm{~m}$. The frequency range in which the SSI operates is shaded in gray.

$m_{v}=0.01 \%$ and to $4 \mathrm{~cm}$ for $m_{v}=1 \%$ at $16 \mathrm{GHz}$. Compared to $16 \mathrm{GHz}$, the penetration depth increases by two orders of magnitude at $1 \mathrm{GHz}$. For dry snow, the absorption is very weak, resulting in penetration depths of $10-20 \mathrm{~m}$ for $\rho_{\mathrm{s}}=0.3 \mathrm{~g} / \mathrm{cm}^{3}$ at $16 \mathrm{GHz}$ and can reach several hundreds of meters for frequencies below $1 \mathrm{GHz}$. The penetration depth over frequency is plotted for different water contents in Fig. 5(right), according to the microwave emission model of layered snowpacks (MEMLS), [43], [45]. In order to apply our method on the data of the SSI, which operates between 9.2 and $17.8 \mathrm{GHz}$, penetration and consequently dry snow with $m_{v}<0.01 \%$ is required.

Volume scattering, which would decrease the penetration depth, can be neglected, as long as dielectric inhomogeneities (ice lenses and pipes, density variations) contained in the snow volume are much smaller than the radar wavelength. The dashed lines in Fig. 5(right) show the penetration depth due to volume scattering for different snow grain sizes. The optical grain diameter $D_{0}$ is related to the exponential correlation coefficient $p_{\mathrm{ex}} \approx 0.16 \ldots 0.4 D_{0}$ as shown in [44] and is equivalent to $p_{\mathrm{ec}}$ used in MEMLS [43]. The largest values of $\mathrm{p}_{\mathrm{ex}} \approx 0.3 \mathrm{~mm}$ were observed for depth hoar [44]. Ice inclusions on the centimeter-scale, depth hoar, or clumpy snow fallen from vegetation are assumed to be the main sources for surface or volume scattering at frequencies below $20 \mathrm{GHz}$.

\section{B. Snow Density}

The propagation speed of microwaves in dry snow depends on snow density. The density $\rho_{\mathrm{s}}$ as used in (1) and (3) was defined by the product of ice volume fraction $f_{v}$ and ice density $\rho_{\text {ice }}$. Note that $\rho_{\mathrm{s}}$ approximates the volumetric mass density of snow $\rho_{\text {snow }}=\rho_{\text {ice }} \cdot f_{\mathrm{v}}+\rho_{\text {air }} \cdot\left(1-f_{\mathrm{v}}\right)$ by neglecting the density of air $\rho_{\text {air }}$. Snow density, which is measured in the field by weighing, results in $\rho_{\mathrm{s}}^{\prime}=f_{\mathrm{v}} \cdot\left(\rho_{\text {ice }}-\rho_{\text {air }}\right)$ due to the buoyancy in air and approximates consequently $\rho_{\text {snow }}$ as well. However, both approximations deviate less that $0.002 \mathrm{~g} / \mathrm{cm}^{3}$ from $\rho_{\text {snow }}$. Hence, they do not affect SWE measurements significantly.
For fresh snow, the density ranges between 0.03 and $0.12 \mathrm{~g} / \mathrm{cm}^{3}$ [46], [47]. The density increases by settling and metamorphosis with time, so that densities of $0.2-0.5 \mathrm{~g} / \mathrm{cm}^{3}$ are commonly observed at the end of a winter season [48]-[51]. Seasonal snow almost never exceeds the critical density $\rho_{\text {crit }}=$ $0.55 \mathrm{~g} / \mathrm{cm}^{3}$ in which ice grains are arranged in a random-closed packed structure [52], [53]. Only deep firn on glaciers and ice sheets reaches the pore-closing density of $0.83 \mathrm{~g} / \mathrm{cm}^{3}$ by sintering and diffusion. The density $0.917 \mathrm{~g} / \mathrm{cm}^{3}$ of solid ice is obtained by high pressure [53], [54]. In the snow pit at the test site, a snow density of $0.1 \mathrm{~g} / \mathrm{cm}^{3}$ was measured in early winter, which increased to $0.3 \mathrm{~g} / \mathrm{cm}^{3}$ shortly before snow melt. Snow density is never completely homogeneous but varies horizontally and vertically [55], [56]. Horizontal variations on the meter-scale can be addressed by the high spatial resolution of an active microwave sensor, whereas vertical variations are addressed in Section IV-G.

\section{MEthod}

This section describes a method to determine the water equivalent of an accumulating dry snow pack from time series of differential interferograms. The method is based on the work of [15], but extends it with a linear relation between phase delay and $\triangle \mathrm{SWE}$, which-contrary to previous publications-does not depend on snow density. In contrast to Guneriussen et al. [15], who considered how snow affects InSAR-based elevation models, our method is optimized to determine large $\triangle \mathrm{SWE}$ from time series of differential interferograms.

The temporal integration of differential interferograms avoids the problem of phase wrapping, minimizes decorrelation, and can measure phase differences of many hundred radians. The method is insensitive to orbit uncertainties and atmospheric disturbances; therefore, it is well suited for airand space-borne sensors. The method is limited to dry snow, as a sufficiently low liquid water content is required that microwaves can still penetrate the snow volume. Further, the radar wavelength must be significantly larger than the snow grain size or other inhomogeneities or inclusions in the snow pack, so that volume scattering can be neglected. Although the presented method is easier to apply for lower frequencies, the temporal resolution of the SSI of only $4 \mathrm{~h}$ allowed us to apply this method even at $16 \mathrm{GHz}$. The successful application of this methods demonstrates not only a new method to determine accurately large $\triangle \mathrm{SWE}$, but also shows that volume scattering can still be neglected at such high frequencies as $16 \mathrm{GHz}$.

In the following section, we describe the general method how to take advantage of a series of differential interferograms to determine the total phase-delay induced by a dry snow pack and discuss how the method can be applied for space-borne sensors. Then, we extend the basic method with a multifrequency approach to reconstruct lost phase cycles, which occur at high radar frequencies and for large $\triangle \mathrm{SWE}$. We show that $\triangle \mathrm{SWE}$ is an almost linear function of phase difference, and analyze the relevant approximations with respect to snow density and incidence angle. We finish this section by extending the method to a snow pack with an arbitrary number of layers. 


\section{A. Integration of the Differential Phase}

The integration of phase differences obtained from a time series of differential interferograms makes it possible to separate phase fluctuations, which are not correlated in time, from phase drifts which increase or decrease significantly in time.

Definition 1: Let $\phi_{\text {signal }}(t)$ be a phase signal, which increases over time, reaches values of many radians and is not wrapped (not given by modulo $2 \pi$ ).

Definition 2: Let $\phi_{\text {fluct. }}(t)$ be a phase fluctuation, which fluctuates by a few radians around zero.

The total phase signal is then given as

$$
\phi(t)=\phi_{\text {signal }}(t)+\phi_{\text {fluct. }}(t) .
$$

With differential interferometry, the absolute phase difference cannot be determined. Only the relative phase difference modulo $2 \pi$ is measurable. When two measurements are available, one at $t=t_{0}$ and one at $t=t_{1}$, the measured phase difference would be

$$
\begin{aligned}
\phi\left(t_{1}, t_{0}\right)= & {\left[\left(\phi_{\text {signal }}+\phi_{\text {fluct. }}\right)\left(t_{1}\right)\right.} \\
& \left.-\left(\phi_{\text {signal }}+\phi_{\text {fluct. }}\right)\left(t_{0}\right)\right] \bmod 2 \pi .
\end{aligned}
$$

As a result of the modulo operation, the information $\phi_{\text {signal }}$ is now covered by the unknown fluctuation $\phi_{\text {fluct. }}$ and cannot be retrieved from $\phi\left(t_{1}, t_{0}\right)$. However, with an infinitely dense sampling in time, the difference (5) takes the form of a differential $\mathrm{d} \phi$, which makes it possible to retrieve the unwrapped phase signal by integrating the differential phase with respect to time

$$
\begin{aligned}
\phi\left(t_{1}, t_{0}\right)=\int_{\phi_{0}}^{\phi_{1}} \mathrm{~d} \phi & =\int_{t_{0}}^{t_{1}} \frac{\mathrm{d}}{\mathrm{d} t}\left(\phi_{\text {signal }}+\phi_{\text {fluct. }}\right)(t) \\
& =\phi_{\text {signal }}\left(t_{1}, t_{0}\right)+\phi_{\text {fluct. }}\left(t_{1}, t_{0}\right) .
\end{aligned}
$$

Phase wraps are hence avoided and the original signal $\phi_{\text {signal }}(t)$ can be extracted. By definition of the two signals, the signal-to-noise ratio increases for an increasing total phase difference, as the sum of fluctuations does not increase due to their mean value around zero. In a realistic case, an infinitely dense sampling will be replaced by a discrete sampling with an interval of $\Delta t=t_{i+1}-t_{i}$. As long as both the signal $\phi_{\text {signal }}(t)$ and the fluctuations $\phi_{\text {fluct. }}$ behave continuously in time and vary slow enough that no phase wraps occur, the condition

$$
\left|\left(\phi_{\text {signal }}+\phi_{\text {fluct. }}\right)\left(t_{i+1}\right)-\left(\phi_{\text {signal }}+\phi_{\text {fluct. }}\right)\left(t_{i}\right)\right|<\pi
$$

is fulfilled. This condition is required, as the phase difference $\phi\left(t_{i+1}\right)-\phi\left(t_{i}\right)$ can only be determined between $\pm \pi$ by applying the two-argument variant of the arctangent on the complex-valued interferometric coherence. For high radar frequencies and heavy snowfall between two acquisitions, this condition can be violated which results in phase-wrapping errors. As shown in Section IV-E, this condition can be circumvented, and lost phase cycles can be recovered by applying a multifrequency approach.
As long as condition (7) is fulfilled or lost phase cycles can be recovered, (6) can be replaced by

$$
\begin{aligned}
\phi\left(t_{N}, t_{0}\right) & =\sum_{i=0}^{i=N}\left(\phi_{\text {signal }}+\phi_{\text {fluct. }}\right)\left(t_{i+1}\right)-\left(\phi_{\text {signal }}+\phi_{\text {fluct. }}\right)\left(t_{i}\right) \\
& =\phi_{\text {signal }}\left(t_{N}, t_{0}\right)+\phi_{\text {fluct. }}\left(t_{N}, t_{0}\right)
\end{aligned}
$$

which is applicable for acquisitions done with a finite sampling interval.

\section{B. Coherence Considerations}

A key requirement for the method is that the interferometric coherence is maintained between two succeeding acquisitions. If the coherence is lost, two consecutive time series have to be joined, which are connected by an incoherent gap where the phase difference is lost. Even when the missing phase difference is set to zero, phase noise from the adjacent interferograms before and after the incoherent gap does not cancel out, as it would be the case for a completely coherent time series. Too many incoherent gaps will, therefore, degrade the overall signal-to-noise ratio.

A main reason for coherence loss of snow-covered terrain is a change of liquid water content in the snow volume due to positive temperatures, melting, or rain. Coherence loss during temperatures below zero can be observed when strong winds lead to a redistribution of snow. Both effects, melting and redistribution, cause a change in SWE. Coherence loss at constant SWE might be observable when, e.g., weak layers in the snow structure collapse by gravity or external forces. Also, vegetation above the snow cover can influences the coherence, when plants deform by the weight of snow or just by wind. Consequently, interpolating incoherent gaps by zero or nonzero phase values has to be done carefully to avoid additional errors in SWE estimation.

In order to minimize the loss of coherence while retaining the sensitivity to small changes in SWE, the radar frequency and the temporal resolution must be chosen appropriately. High frequencies allow an accurate retrieval of $\triangle \mathrm{SWE}$ but are very sensitive to wet snow and phase wrapping errors. With lower frequencies, the coherence decays slower, liquid water has a less limiting effect on the penetration depth and phase-wrapping errors are less likely. Still, SWE retrieval is less accurate due to longer wavelengths. The optimal radar frequency and sampling interval have to be chosen according to the expected air temperatures and according to the expected amount of snowfall between two acquisitions.

\section{Initial Phase Value $\phi\left(t_{0}\right)$}

With the described method it is only possible to determine a time series of phase differences $\phi\left(t, t_{0}\right)$ starting at time $t_{0}$, which is then used to determine $\Delta \operatorname{SWE}\left(t, t_{0}\right)$. For the determination of the total $\operatorname{SWE}(t)$, the first acquisition must be done before the first snowfall and coherence should never be lost. However, quite often winter starts with a mix of warm and cold temperatures, leading to some accumulation 
of wet snow, which freezes when temperatures drop constantly below zero. As wet snow leads to a strong decrease in coherence, our methods works best for regions which are covered only with dry snow. In order to capture this initial accumulation of wet snow, low enough radar frequencies must be used, which are less sensitive to the liquid water content of snow so that coherence is maintained during the early winter precipitation.

For higher frequencies, an assumption has to be made to estimate the initial quantity $\operatorname{SWE}\left(t_{0}\right)$ to determine the total $\operatorname{SWE}(t)=\Delta \mathrm{SWE}\left(t, t_{0}\right)+\operatorname{SWE}\left(t_{0}\right)$. A wrong assumption about $\operatorname{SWE}\left(t_{0}\right)$ adds an additional error source to the method. However, often early winter snow melts and contributes not or only little to the winter snow pack.

\section{Application on Air-and Space-Borne Sensors}

For single-frequency systems, (7) is very restrictive and is only easy to fulfill for ground-based instruments with a high temporal resolution or low enough frequencies. For airand space-borne systems, reference points (corner reflectors or other permanent scatterers not affected by snow or even distributed targets like snow free mountain valleys) are necessary to reduce orbit uncertainties, system drifts and atmospheric delays below $\pi$. Phase errors larger than $\pi$ are acceptable if they increase continuously with distance from a reference point (as it is, e.g., the case for atmospheric or ionospheric delays) to allow spatial phase unwrapping. Phase errors fulfilling Definition 2 average out compared to the signal of interest which fulfills Definition 1.

Unfortunately, systematic phase errors resulting, e.g., from imprecise digital elevation models do not fulfill Definition 2 and mix with the signal of interest $\phi_{\text {signal }}$. However, the phase error due to topography (height sensitivity given by $\mathrm{d} \phi / \mathrm{d} z=$ $\frac{4 \pi B_{\perp}}{\lambda R \sin \theta}$ [33]) can be kept small if the interferometric baseline $B_{\perp}$ is much smaller than the product $\lambda \cdot R$ of radar wavelength and distance $R$ to the target. Soil deformation on the order of millimeter would bias the snow signal by a few millimeter but can be neglected according to (2).

Coherence loss and lost phase cycles are currently the major drawbacks for the application of differential interferometry on air- and space-borne acquisitions. We analyzed time series of differential interferograms taken by the satellite TerraSAR-X at $9.65 \mathrm{GHz}$ over snow-covered terrain and observed a strong coherence loss within the repeat time of 11 days. Furthermore, the phase difference at X-band wraps from $\pi$ to $-\pi$ already at a change in SWE below $9 \mathrm{~mm}$, which is possible to happen within 11 days. However, a less sensitive method has been suggested to estimate the depth of fresh snow by using polarimetric phase differences [58]. This method could help to estimate lost phase cycles. Further, a reduction of the radar frequency to $1 \mathrm{GHz}$ makes phase-wrapping very unlikely as phase-wraps occur not until a $\triangle \mathrm{SWE}$ of more than $80 \mathrm{~mm}$. Therefore, air- and space-borne systems are suited to apply our method when low enough frequencies are used. Low-frequency systems with high repeat times like TanDEM-L [34] are promising candidates.

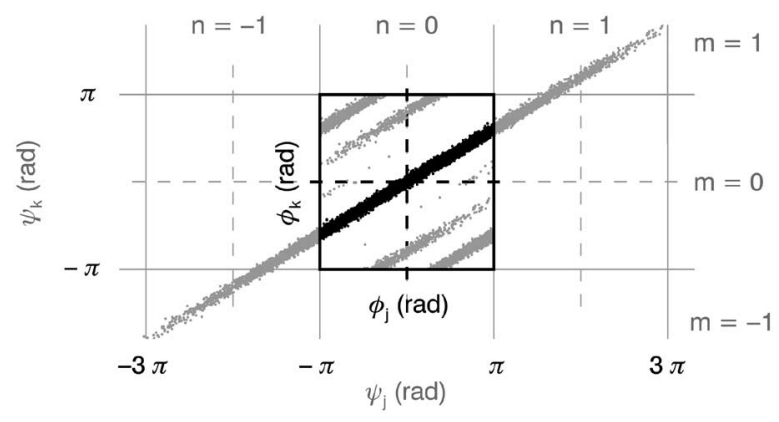

Fig. 6. Displacement, measured with two different frequencies $\left(f_{j}\right.$ and $\left.f_{k}\right)$ by differential interferometry, is represented by a phase tuple $\left(\psi_{j}, \psi_{k}\right)$. Phases which exceed $\pm \pi$ (gray) are wrapped into a square between $\pm \pi$. As long as the phase tuples $\left(\phi_{j}, \phi_{k}\right)$ which belong to different multiples of $2 \pi$ do not occupy the same space between $\pm \pi$, lost phase cycles can be recovered.

\section{E. Multifrequency/Delta-k Extension}

For frequencies of several $\mathrm{GHz}$, the probability of phasewrapping caused by large changes in SWE increases. In this section, we describe how lost phase cycles can be recovered with a multifrequency approach to circumvent the limiting condition of (7). The approach applies for radar sensors, which either have a sufficiently large bandwidth or which operate in at least two different frequency bands. This approach is closely related to delta-k and multifrequency methods to determine the absolute phase of an SAR interferogram [24], [35], [36].

Let $\Delta L$ be an optical path delay of the signal. Let $f_{j}$ and $f_{k}$ be the center frequencies of the two frequency bands with $j, k=1, \ldots, N$ with $N$ being the total number of available frequency bands. For the $j$ th frequency band, the resulting phase difference is then given by $\psi_{j}=2 \pi \Delta L / \lambda_{j}$, which can exceed $2 \pi$ for delays larger than the wavelength $\lambda_{j}$. As the twoargument variant of the arctangent returns only values between $\pm \pi$ the measured phase differences $\phi_{j}$ and $\phi_{k}$ for two different frequency bands are related to the total phase differences $\psi_{j}$ and $\psi_{k}$ by

$$
\begin{aligned}
& \psi_{j}=\phi_{j}+n \cdot 2 \pi=2 \pi \frac{\Delta L}{\lambda_{j}} \\
& \psi_{k}=\phi_{k}+m \cdot 2 \pi=2 \pi \frac{\Delta L}{\lambda_{k}}
\end{aligned}
$$

with two integer numbers $n, m \in \mathbb{Z}$. The frequency ratio $f_{j} / f_{k}$ must not be a too simple fraction $a / b$ (with not too small integers $a, b \in \mathbb{N})$ as, otherwise, phase-tuples $\left(\phi_{j}, \phi_{k}\right)$ are mapped on each other by phase wrapping in the space between $-\pi$ and $\pi$ (Fig. 6) for different unwrapped phase values $\left(\psi_{j}, \psi_{k}\right)$. To avoid ambiguous mapping, the relative difference of two frequencies $\frac{1}{2}\left|f_{j}-f_{k}\right| /\left|f_{j}+f_{k}\right|$ must be larger than the relative phase noise $\phi_{\text {noise }} /(2 \pi)$. The unwrapped phase values $\left(\psi_{j}, \psi_{k}\right)$ can be determined by solving

$$
\left|\left(\phi_{j}+n \cdot 2 \pi\right)-\frac{f_{j}}{f_{k}}\left(\phi_{k}+m \cdot 2 \pi\right)\right| \leq \phi_{\text {noise }}
$$

for the two integer numbers $n, m$ which are closest to zero. For a noise-free system, $\phi_{\text {noise }}$ would be zero. In a realistic system, $\phi_{\text {noise }}$ corresponds to the expected phase noise, which depends on the magnitude of the coherence and the system. Solving 


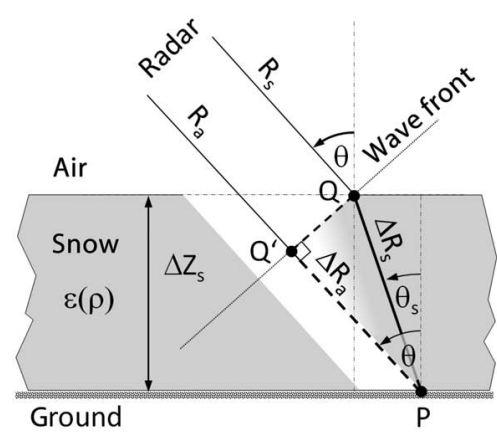

Fig. 7. The phase delay due to snow can be calculated from the optical path length difference $\Delta R=n_{\text {snow }} \Delta R_{\mathrm{s}}-\Delta R_{\mathrm{a}}$. Microwaves propagate the distance $\Delta R_{\mathrm{S}}$ (solid line) in snow with the permittivity $\epsilon\left(\rho_{\mathrm{S}}\right)=n_{\text {snow }}^{2}$ and the distance $\Delta R_{\mathrm{a}}$ (dashed) in air. The resulting phase difference is given in (14). $R_{\mathrm{S}}=R_{\mathrm{a}}$ is the distance from the sensor to the common wave front.

(11) corresponds to finding a line parametrized by $\psi_{k}\left(\psi_{j}\right)$ for a two-frequency system in a (two-dimensional) 2-D-space. When more frequencies are available, the line $\psi_{k}\left(\psi_{j_{1}}, \ldots, \psi_{j_{N-1}}\right)$ will be defined in an $\mathrm{N}$-dimensional space. This has the advantage that phase-tuples $\left(\phi_{1}, \ldots, \phi_{N}\right)$ are much less likely mapped onto each other which simplifies the determination of the integer tuples $(n, m, \ldots)$ to determine the absolute phase values.

\section{F. Proportionality of the Differential Phase and $\triangle S W E$}

This section shows that there is a nearly linear dependence between $\triangle \mathrm{SWE}$ and the signal delay, measured by the differential phase $\Delta \Phi$. The signal delay can be derived from the geometry illustrated in Fig. 7. Let $P$ be a point on the ground which is covered by snow of a height $\Delta Z_{\mathrm{s}}$. After traveling the distance $R_{\mathrm{s}}$ from the sensor, an optical beam with plane wave fronts will be refracted at point $Q$ to reach point $P$ after propagating a distance $\Delta R_{\mathrm{s}}$ in snow with permittivity $\epsilon$. For snow free conditions, after traveling $R_{\mathrm{a}}=R_{\mathrm{s}}$ from the sensor, the optical beam will pass the point $Q^{\prime}$ without refraction, and will reach point $P$ after propagating the distance $\Delta R_{\mathrm{a}}$ in air. The difference $\Delta R$ in the optical path length, which describes the delay due to snow relative to snow free conditions, is given by

$$
\Delta R=\left(R_{\mathrm{s}}+\sqrt{\epsilon} \cdot \Delta R_{\mathrm{s}}\right)-\left(R_{\mathrm{a}}+\Delta R_{\mathrm{a}}\right) .
$$

Replacing first $\Delta R_{\mathrm{s}}=\Delta Z_{\mathrm{s}} / \cos \theta_{\mathrm{s}}, \Delta R_{\mathrm{a}}=\Delta R_{\mathrm{s}} \cos (\theta-$ $\left.\theta_{\mathrm{s}}\right)$ and applying the cosine addition theorem and rewriting then $\sin \theta=n \sin \theta_{\mathrm{s}}$ by Snell's law ( $n=\sqrt{\epsilon}$ being the refractive index of snow) and replacing $\cos \theta_{\mathrm{s}}=\sqrt{1-\sin ^{2} \theta_{\mathrm{s}}}$ leads to

$$
\begin{aligned}
\Delta R & =-\Delta Z_{\mathrm{s}}\left(\cos \theta+\frac{\sin \theta \sin \theta_{\mathrm{s}}-n}{\cos \theta_{\mathrm{s}}}\right) \\
& =-\Delta Z_{\mathrm{s}}\left(\cos \theta-\sqrt{\epsilon-\sin ^{2} \theta}\right) .
\end{aligned}
$$

The same path delay results when the depth of an already existing snow cover changes by a positive or negative $\Delta Z_{\mathrm{s}}$ due to snow redistribution or snowfall while the underlying layers
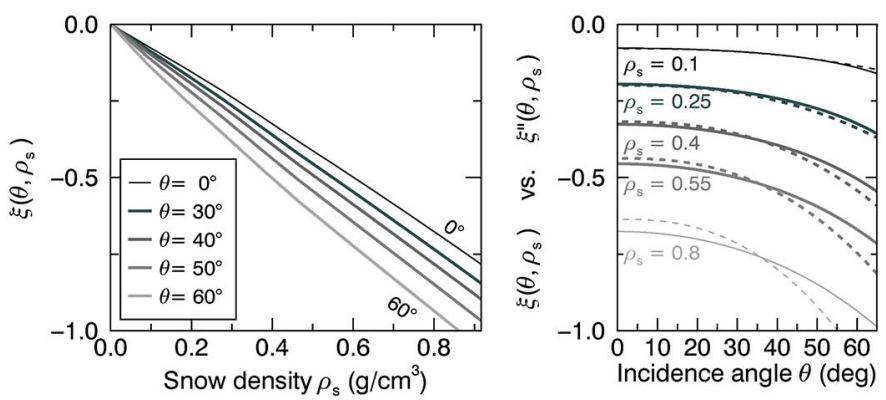

Fig. 8. Left: the expression $\xi\left(\theta, \rho_{\mathrm{s}}\right)$ as defined in (14) has an almost linear dependence on snow density for a wide range of incidence angles $\theta$. Right: comparison of $\xi\left(\theta, \rho_{\mathrm{S}}\right)$ (solid lines) with the approximation $\xi^{\prime \prime}\left(\theta, \rho_{\mathrm{S}}\right)$ (dashed lines) for $\alpha=1$ and different densities over incidence angle.

remain unchanged. In both cases, the resulting two-way phase difference $\Delta \Phi_{\mathrm{s}}=2 \cdot 2 \pi \frac{\Delta R}{\lambda}$ is given by

$$
\Delta \Phi_{\mathrm{s}}=-2 k_{i} \Delta Z_{\mathrm{s}} \underbrace{\left(\cos \theta-\sqrt{\epsilon-\sin ^{2} \theta}\right)}_{=: \xi\left(\theta, \rho_{\mathrm{s}}\right)} .
$$

The incoming radar beam vector is defined by $k_{i}=\frac{2 \pi}{\lambda}$ with $\lambda$ being the central wavelength of the radar. The radar incidence angle with respect to the snow surface is given by $\theta$. The same expression was derived by [15, eq. (6)] and was approximated for the special case of ERS acquisitions and low snow densities [15, eq. (8)]. Here, we analyze the linearity of the term $\xi\left(\theta, \rho_{\mathrm{s}}\right)$ to derive a more general, still simple and invertible linear function $\Delta \Phi_{\mathrm{S}}(\Delta \mathrm{SWE})$.

The snow density dependent term $\xi\left(\theta, \rho_{\mathrm{s}}\right)$ shows an almost linear dependence on $\rho_{\mathrm{s}}$ [Fig. 8(left)]. However, a good series expansion of the square root fails due to a limited convergence radius of the Taylor series, consequently $\xi$ can only be approximated for small $\rho_{\mathrm{s}}$ and $\theta$. For $\rho_{\mathrm{s}}<0.4 \mathrm{~g} / \mathrm{cm}^{3}$, with respect to (3), the factor $\xi$ can be rewritten as

$$
\xi^{\prime}\left(\theta, \rho_{\mathrm{s}}\right)=\cos \theta\left(1-\sqrt{1+\frac{a_{1} \rho_{\mathrm{s}}+a_{3} \rho_{\mathrm{s}}^{3}}{\cos ^{2} \theta}}\right) .
$$

To first-order of $\rho_{\mathrm{s}}$ and for small $\theta,(15)$ can be approximated by

$$
\xi^{\prime}\left(\theta, \rho_{\mathrm{s}}\right) \doteq-\frac{a_{1} \rho_{\mathrm{s}}}{2 \cos \theta} .
$$

The expression $\xi^{\prime}$ deviates significantly for larger snow densities from $\xi$ as defined in (14). However, it can be shown numerically that (16) can be replaced by a very similar expression, which is valid for all possible densities of snow and ice and a wide range of incidence angles and which deviates only by a few percent from the exact expression $\xi$. It is given by

$$
\xi^{\prime \prime}\left(\theta, \rho_{\mathrm{s}}\right):=-\frac{\alpha}{2}\left(1.59+\theta^{5 / 2}\right) \cdot \rho_{\mathrm{s}} / \rho_{\mathrm{w}} .
$$

The factor 1.59 was determined empirically but coincides with $a_{1}$ in (3) when approximating (14) for low densities and small incidence angles. For a fixed $\alpha=1$, the approximation $\xi^{\prime \prime}$ deviates from the exact solution $\xi$ by a few percent at large 

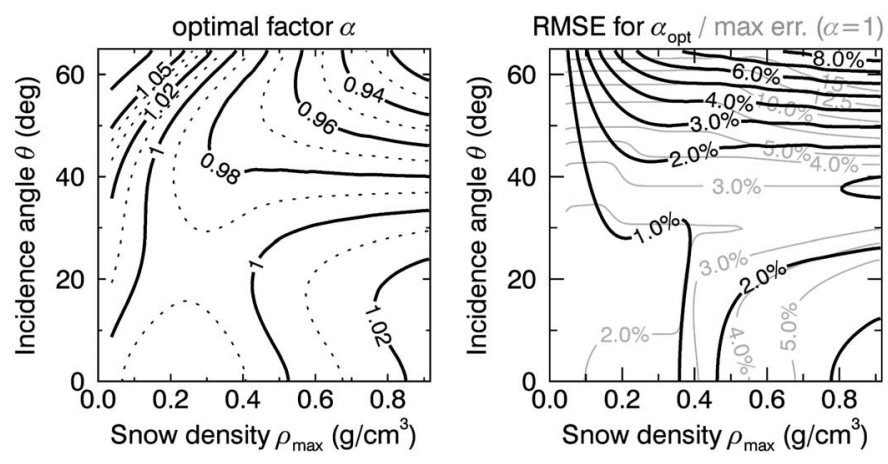

Fig. 9. Left: the optimal value of $\alpha$, used in (17) to minimize the RMSE of $\left|\xi^{\prime \prime}-\xi\right|$, depends on incidence angle and the maximum expected snow density $\rho_{\mathrm{s}} \leq \rho_{\text {max }}$. Right: using the optimal value $\alpha_{\text {opt }}$, the RMSE of $\left|\xi^{\prime \prime}-\xi\right|$ is below $3 \%$ for $\theta<50^{\circ}$ (black contours). For a fixed $\alpha=1$, the maximum error is below $10 \%$ for $\theta<50^{\circ}$ but increases significantly for larger incidence angles (gray contours).

$\theta$ and $\rho_{\mathrm{s}}$ [Fig. 8(right)]. To compensate for this deviation, an optimal $\alpha$ was determined by minimizing the RMSE of $\left|\xi-\xi^{\prime \prime}\right|$ within the considered range of snow densities, $0 \leq \rho_{\mathrm{s}} \leq \rho_{\max }$, and for a fixed $\theta$. Fig. 9(left) shows the optimal values for $\alpha$. The optimal $\alpha$ is very close to 1 for common incidence angles $\left(<50^{\circ}\right)$. Interestingly, the nonlinear form of $\xi$ compensates the nonlinear dependence of $\epsilon\left(\rho_{\mathrm{s}}\right)$ so that $\xi^{\prime \prime}$, using $\alpha_{\mathrm{opt}}$, deviates not more than $3 \%$ RMS from the exact solution $\xi$ for all snow densities and incidence angles $\theta<50^{\circ}$ [Fig. 9(right)]. For a fixed $\alpha=1$ and $\theta<50^{\circ}$, the maximum error $\left|\xi-\xi^{\prime \prime}\right| / \xi$ is below $10 \%$. For the SnowScat experiment with $\rho_{s}<0.4 \mathrm{~cm}^{3}$, $\theta \leq 65^{\circ}$ and using $\alpha_{\text {opt }}$ an error below $7 \%$ is expected. For the special case of ERS data $\left(\theta=23^{\circ}\right)$ and snow of very low density $(\alpha=1.02), \xi^{\prime \prime}\left(\theta, \rho_{\mathrm{s}}\right)$ converges to the factor $0.87 \cdot \rho_{\mathrm{s}}$ which was obtained by [15].

A linear relation between the differential phase $\Delta \Phi_{\mathrm{s}}$ and $\triangle \mathrm{SWE}$ is now obtained by replacing $\xi$ with $\xi^{\prime \prime}$ in (14) and writing (1) as $\Delta \mathrm{SWE}=\Delta Z_{\mathrm{s}} \cdot \rho_{\mathrm{s}} / \rho_{\mathrm{w}}$ using a constant snow density $\rho_{\mathrm{s}}$ :

$$
\Delta \Phi_{\mathrm{s}}=2 k_{i} \cdot \frac{\alpha}{2}\left(1.59+\theta^{5 / 2}\right) \cdot \Delta \mathrm{SWE} .
$$

The sensitivity analysis (Fig. 9) shows that this approximation is valid for a wide range of incidence angles and densities.

\section{G. Effect of Layered Snow Pack}

Equation (14) and its approximation (18) were derived by assuming a constant snow density. This section extents the description to a multilayer snow pack with different densities as it is typically found in nature.

The geometry of a multilayer system is shown in Fig. 10 . An electromagnetic wave starting from the point $Q_{1}$ on the common wave front is refracted at each layer boundary until it reaches the point $P$ on the ground. The snow-free reference path (straight line connecting $Q^{\prime}$ on the common wave front and $P$ ) can be split into parallel sections $\Delta R_{\mathrm{a}, j}$ (dashed) of the same total length. The sections $\Delta R_{\mathrm{a}, j}$ correspond to the snow free optical path, which would have a single layer in the geometry of

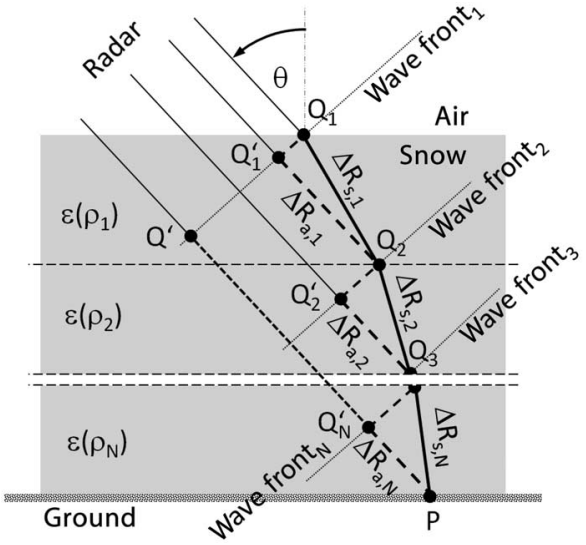

Fig. 10. The Phase delay for a multilayer system is given by the sum of individual delays per layer. The individual delays are described by (14) using $\epsilon=\epsilon\left(\rho_{j}\right)$ for each specific layer $j$, but keeping $\theta$ as the radar incidence at the snow surface. The density $\rho_{j}$ does not necessarily have to increase toward the ground.

Fig. 7. By summing the optical path-differences for each layer, the total path length-difference $\Delta R_{\text {tot }}$ is given as

$$
\Delta R_{\mathrm{tot}}=\sum_{j=1}^{N}\left(\Delta R_{\mathrm{s}, j}-\Delta R_{\mathrm{a}, j}\right) .
$$

The delay caused by each layer can be described directly by (14). The propagation angle in the first layer of snow is given by the radar incidence angle $\theta$ and Snell's law $n_{\text {air }} \sin \theta=$ $n_{1} \sin \theta_{1}$. The incidence angle in the next layer is given by the refraction indices of the first and second layer by $n_{1} \sin \theta_{1}=$ $n_{2} \sin \theta_{2}$ and so on, so that the propagation angle of the $j$ th layer can be calculated with respect to the original radar incidence angle $\theta$ by

$$
n_{\text {air }} \sin \theta=n_{j} \sin \theta_{j} .
$$

Equation (14) describes the phase difference measured from a common wave front to the target, once measured perpendicular to the wavefront (free space path, $\overline{Q^{\prime} P}$ in Fig. 7) and once under the propagation angle in the medium with dielectric constant $\epsilon$ (path in snow, $\overline{Q \ldots P}$ in Fig. 7). This principle applies at each wavefront $1 \ldots N$ in a layered medium (Fig. 10). For each layer, the free space path is given by $\overline{Q_{j}^{\prime} Q_{j+1}}$ and the path in snow by $\overline{Q_{j} Q_{j+1}}$. It follows that the total expected phase difference for $N$ layers can be expressed as

$$
\Delta \Phi_{\mathrm{s}}=-2 k_{i} \sum_{j=1}^{N} \Delta Z_{\mathrm{s}, j}\left(\cos \theta-\sqrt{\epsilon_{j}-\sin ^{2} \theta}\right) .
$$

Approximation (17) can be applied here as well, as the radar incidence angle $\theta$ does not depend on the snow pack. It follows that (21) is equivalent with (18), when writing terms, which do not depend on $j$, in front of the sum:

$$
\begin{aligned}
\Delta \Phi_{\mathrm{S}} & =2 k_{i} \frac{\alpha}{2}\left(1.59+\theta^{5 / 2}\right) \cdot \sum_{j=1}^{N} \Delta Z_{\mathrm{s}, j} \cdot \rho_{\mathrm{s}, j} / \rho_{\mathrm{W}} \\
& =2 k_{i} \frac{\alpha}{2}\left(1.59+\theta^{5 / 2}\right) \cdot \Delta \mathrm{SWE}
\end{aligned}
$$




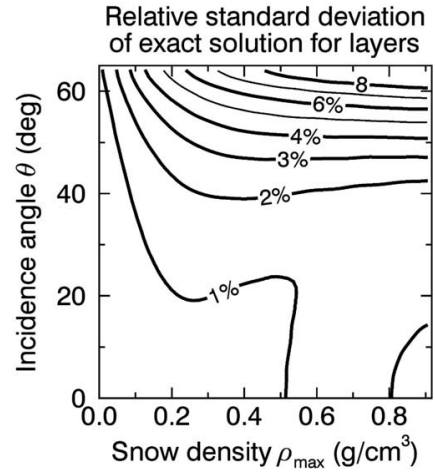

Relative RMSE betw. exact solution and approximation $(\alpha=1)$ for layers

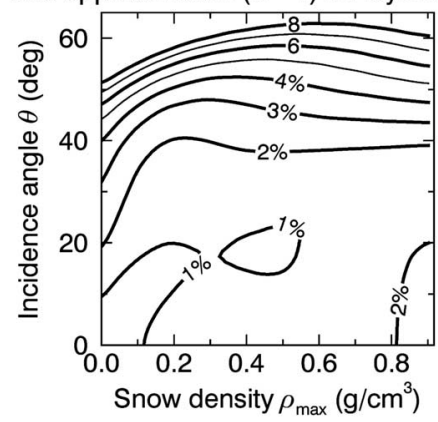

Fig. 11. Left: relative standard deviation $\sigma_{\Delta \Phi_{\mathrm{s}}} /\left\langle\Delta \Phi_{\mathrm{s}}\right\rangle$ of the differential phase with respect to a system of 10 layers with a fixed, total $\Delta$ SWE but random thickness and density. The density of each layer was chosen between 0 and $\rho_{\max }$. Right: relative RMSE between $\Delta \Phi_{s}$ from the exact solution (21) and the approximation (22) for $\alpha=1$ (fixed) for the system of 10 layers.

Hence, assuming that (17) is valid, there is a linear relation between $\Delta$ SWE and the differential phase $\Delta \Phi_{\mathrm{s}}$ for a natural snow pack, which consists of an arbitrary number of layers with different densities.

Due to the slight nonlinear dependence of (14) on $\rho_{\mathrm{s}}$, different phase differences $\Delta \Phi_{\mathrm{s}}$ are expected when the total $\Delta \mathrm{SWE}$ is kept constant, but layers with different densities $\rho_{\mathrm{s}, j}$ are assumed. To estimate the expected range of phase values, $\Delta \Phi_{\mathrm{s}}$ was calculated for a system of 10 snow layers with a random density distribution and a random thickness distribution. The layer thickness was uniformly distributed and normalized to get a constant $\Delta \mathrm{SWE}$. The densities $\rho_{\mathrm{s}, j}$ were normal distributed between 0.01 and $\rho_{\max }$, where $\rho_{\max }<\rho_{\text {ice }}$ is the maximum expected snow density, which could occur in the simulated, layered snow pack. The relative standard deviation $\sigma_{\Delta \Phi_{\mathrm{s}}} /\left\langle\Delta \Phi_{\mathrm{s}}\right\rangle$ for the ensemble of 10 random layers with constant $\triangle \mathrm{SWE}$ was found to be below $4 \%$ for all snow densities and $\theta<50^{\circ}$ [Fig. 11(left)]. For the system parameters and snow conditions of the SnowScat experiment, the relative standard deviation is estimated to be below 7\%. The relative RMSE between the exact solution for a multilayer model (21) and the approximation for a fixed $\alpha=1$ (22) is below $6 \%$ for $\theta<50^{\circ}$ [Fig. 11(right)].

Concluding the theory, the analysis of the systematic errors for a single layer and the statistically distributed errors for a multilayer model showed that (22) is a valid approximation, which allows to determine $\triangle \mathrm{SWE}$ with an accuracy of a few percent. For an optimal $\alpha$ and common incidence angles $<50^{\circ}$, the total error can be estimated by summing the errors of Fig. 9 (right) and 11(left): $\sqrt{(3 \%)^{2}+(6 \%)^{2}} \approx$ $7 \%$. For a fixed $\alpha=1$, the total error can be estimated summing the errors of Figs. 9(right), 11(left), and 11(right): $\sqrt{(6 \%)^{2}+(4 \%)^{2}+(6 \%)^{2}} \approx 9 \%$. For the SnowScat using an optimal $\alpha$ and incidence angles up to $65^{\circ}$, a maximum error of $\sqrt{(7 \%)^{2}+(7 \%)^{2}} \approx 10 \%$ can be expected.

\section{Data Processing}

$\triangle \mathrm{SWE}$ was determined by processing raw data of the SSI into differential interferograms, which were then analyzed with the method of Section IV. The required processing steps to determine $\Delta \mathrm{SWE}$ are described in the following sections.

\section{A. Raw Data to Single Look Complex}

For each azimuth and elevation angle, the SSI scanned the full frequency bandwidth, resulting in 2800 IQ-value pairs, one pair per frequency step. Each pair represents the amplitude and phase measured by the receiving antenna with respect to an internal oscillator. The full measured spectrum was windowed with a Hamming window of bandwidth $b w$ to select a center frequency $f$. The bandwidth $b w$ is defined as the full-width-ofhalf-maximum (FWHM) of the Hamming window. The resulting frequency-domain-signal was converted into time-domain by an energy-preserving Fourier transform, obeying Parseval's identity. The time-domain signal $S(r)$ was windowed to valid ranges $r$ between 10 and $29 \mathrm{~m}$, corresponding to the first ground reflection at nadir and a far range reflection at about $\theta=70^{\circ}$. In order to compensate, the decreasing backscatter intensity in range, the amplitude $S(r)$ was multiplied by $r^{2}$. The antenna pattern was not corrected, as it acts as a natural weighting function for the signal-to-noise ratio. As for the interferometric processing only the phase of the signal is of interest, no normalized radar cross section signal $\sigma_{0}$ (NRCS) was processed. Each time-domain signal $S(r)$ measured at time $t$ represents a one-dimensional (1-D) SLC acquisition. Time-series of SLC acquisitions $S(r, t)$ were used in the interferometric processing.

\section{B. Interferometric Processing}

Differential interferograms were formed from the complex coherence $\gamma=|\gamma| \exp ^{i \phi}$ between each pair of acquisitions measured at $t_{1}$ and $t_{2}>t_{1}$. The coherence was calculated as

$$
\gamma\left(t_{2}, t_{1}\right)=\frac{\sum_{r=r_{0}}^{r=r_{1}} S\left(r, t_{2}\right) \cdot S\left(r, t_{1}\right)^{*}}{\sqrt{\left(\sum_{r=r_{0}}^{r=r_{1}}\left|S\left(r, t_{2}\right)\right|^{2}\right) \cdot\left(\sum_{r=r_{0}}^{r=r_{1}}\left|S\left(r, t_{1}\right)\right|^{2}\right)}} .
$$

For two consecutive acquisitions measured at time $t_{i+1}$ and $t_{i}$, the differential phase is given by $\phi=\phi\left(t_{i+1}\right)-\phi\left(t_{i}\right)$. Time series of differential phases were used for summation according to (8). From this equation, the total phase difference $\Delta \Phi_{\mathrm{s}}=$ $\phi\left(t, t_{0}\right)$ was obtained for a given time $t\left(=t_{N}\right)$ during the winter with respect to a reference acquisition at time $t_{0}$ when the dry snow period started.

The size of the coherence window was adapted for two cases: 1) in order to cover the antenna footprint of $1-6 \mathrm{~m}$, a window size of 60-300 pixels was used (depending on incidence angle) and 2) in order to create spatially high resolution maps, a window size of 20 pixels, corresponding to $35 \mathrm{~cm}$ slant-range resolution, was used.

Coregistration can be required if the backscatter-patterns $S(r)$ of both acquisitions are displaced with respect to each other, either by sensor displacement or by a signal delay caused by snow. For interferograms with a temporal baseline of $\Delta t=4 \mathrm{~h}$, no coregistration was required. For larger temporal baselines, coregistration was required when heavy 
snowfall occurred between two acquisitions. For $\Delta t>30$ days, coregistration failed partially due to complete decorrelation.

To minimize decorrelation, a temporal baseline of $4 \mathrm{~h}$ was used to calculate $\Delta \Phi_{\mathrm{s}}$ and to determine $\Delta$ SWE. While the coherence magnitude $|\gamma|$ was always very close to one for dry snow, it was highly reduced during periods of wet snow. Therefore, the reference acquisition was chosen in November when temperatures dropped below zero and the coherence showed stable values close to one. $\Delta \Phi_{\mathrm{s}}$ was summed until April/May, when snow melt caused a sudden loss of the coherence $(|\gamma| \approx 0.4)$, and no reliable phase differences could be obtained any more (a detailed analysis of the coherence is given in Sections VI-E and VI-F).

The phase differences of acquisition pairs with $\gamma<c_{\min }$ were excluded and set to zero. During periods of dry snow, the coherence was always above 0.9 , so that the threshold set to $c_{\min }=0.5 \mathrm{did}$ not affect the calculation of $\Delta \mathrm{SWE}$. However, $\triangle \mathrm{SWE}$ estimates during wet snow periods in November and April were improved by a threshold of 0.5 .

\section{Determination of SWE}

After calculating $\Delta \Phi_{\mathrm{s}}$ by phase integration, the total phase difference was converted into $\Delta \mathrm{SWE}$ according to (18)

$$
\Delta \operatorname{SWE}\left(t, t_{0}\right)=\frac{\Delta \Phi_{\mathrm{s}}\left(t, t_{0}\right)}{\alpha \cdot k_{i}\left(1.59+\theta^{5 / 2}\right)}
$$

The parameter $\alpha$ was chosen according to the incidence angle $\theta$ and for $\rho_{\max }<0.3$ according to Fig. 9 (left). For the time-series analysis, the elevation angle $\theta$ from the instrument settings was used, as only the mean differential phase within the antenna footprint was determined. In order to compare the obtained $\triangle$ SWE with terrestrial laser-scanner data, the incidence angle was calculated for each range sample with respect to the system geometry. The free-space wave vector $k_{i}=\frac{2 \pi}{\lambda}$ follows from the selected central frequency $f$.

The frequency-range of $9-18 \mathrm{GHz}$ in which the SSI operates involves two additional complications: loss of coherence during periods of wet snow as well as phase-wrapping during periods of intense snow fall. Lost phase cycles were reconstructed with the two frequency-approach described in Section IV-E. Coherence loss appeared in early winter until the time $t_{0}$ when the dry snow period started. The loss of coherence made it impossible to determine the initial $\operatorname{SWE}\left(t_{0}\right)$, which accumulated before the time $t_{0}$ and froze afterward. Therefore, $\operatorname{SWE}\left(t_{0}\right)$ was estimated from the GWI and added to $\Delta \operatorname{SWE}\left(t, t_{0}\right)$ obtained from (24) to determine the total $\operatorname{SWE}(t)$.

\section{RESUlTS AND DisCUSSION}

Time series $\Delta \operatorname{SWE}(t)$ were derived at central frequencies of 10.2 and $16.8 \mathrm{GHz}$. Both time series were validated with ground measurements and were compared with each other. Using the two-frequency approach as well as a polarimetric analysis, we show that dry snow is still transparent at $16 \mathrm{GHz}$. In the last two sections, the temporal evolution of the coherence as well as the coherence decay for different snow conditions is discussed.
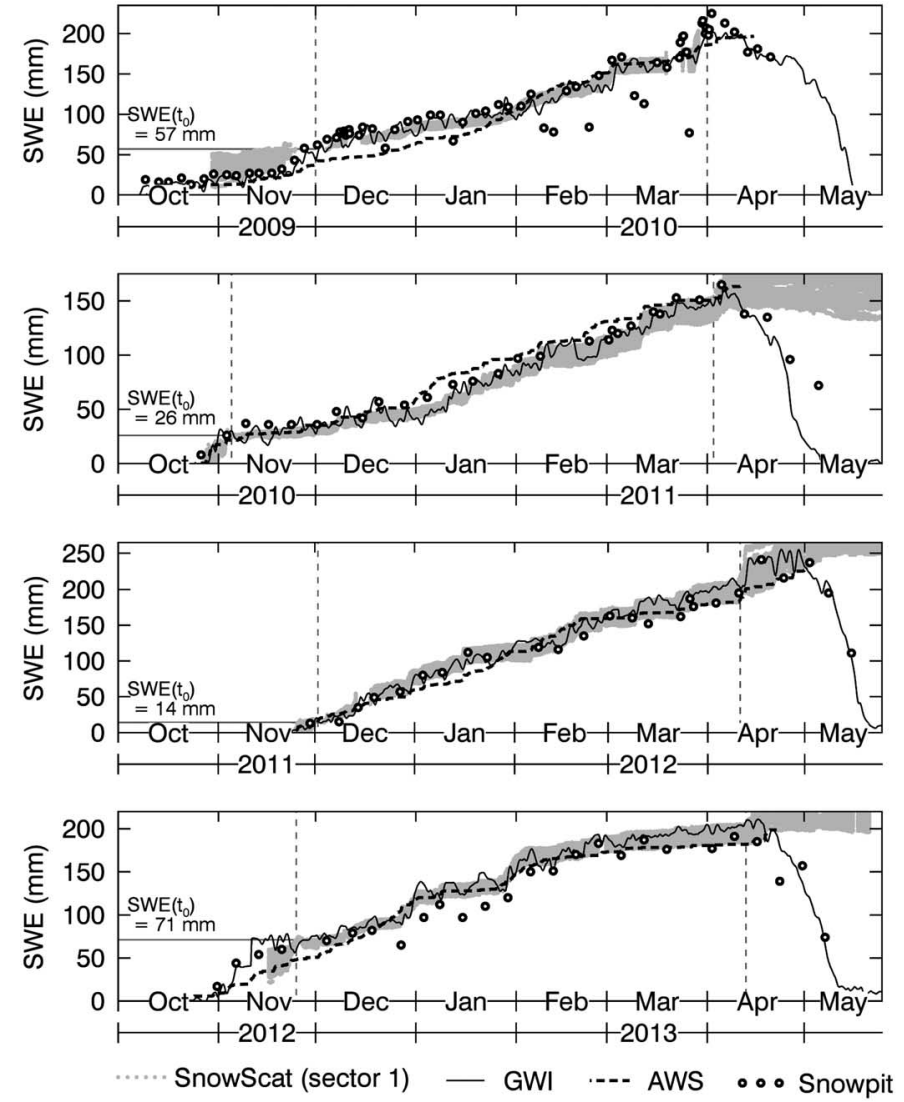

Fig. 12. SWE derived for sector 1 compared to measurements of the GWI, the AWS and the snow pit. The SnowScat data (ensemble of gray lines) were processed using a two-frequency approach with 10.2 and $12.5 \mathrm{GHz}$ and a bandwidth of $2 \mathrm{GHz}$. The coherence threshold was set to 0.5 . The time $t_{0}$, when $\operatorname{SWE}\left(t_{0}\right)$ was set, is indicated by a dashed gray line in November or early December. In April, a second vertical dashed line indicates the onset of snow melt.

\section{A. Time Series of SWE over Four Winter Seasons}

$\Delta \operatorname{SWE}(t)$ derived from the SSI was compared with SWE measurements obtained from the AWS, the GWI and manual SWE measurement from the snow pit. All available data from the SSI, 4 years for sector 1 , and 3 years for sector 2, were processed.

For each sector, time series $\Delta \mathrm{SWE}\left(t, t_{0}\right)$ were calculated separately for each azimuth- and elevation-subsector. The individual time series of each subsector are shown together as an ensemble of gray lines in the background of Figs. 12 and 13. The time $t_{0}$ of the reference acquisition, at which each time series $\Delta \operatorname{SWE}\left(t, t_{0}\right)$ started, is indicated for each year by a vertical dashed line in November or early December. The initial value $\operatorname{SWE}\left(t_{0}\right)$, which was estimated from the GWI, is given for each year above a horizontal gray line. A second vertical dashed line indicates the onset of snow melt in April.

The results of sector 1 obtained at $10.2 \mathrm{GHz}$ (plus $12.5 \mathrm{GHz}$ to recover lost phase cycles) follow accurately the values obtained from the GWI, the AWS and the snowpit measurements during the dry snow period (Fig. 12). Within each winter, $\Delta \operatorname{SWE}\left(t, t_{0}\right)$ reaches values between 150 and $250 \mathrm{~mm}$. Each year in autumn, $15-71 \mathrm{~mm}$ of wet snow accumulated until $t_{0}$, which could not be measured at the frequency spectrum of the 

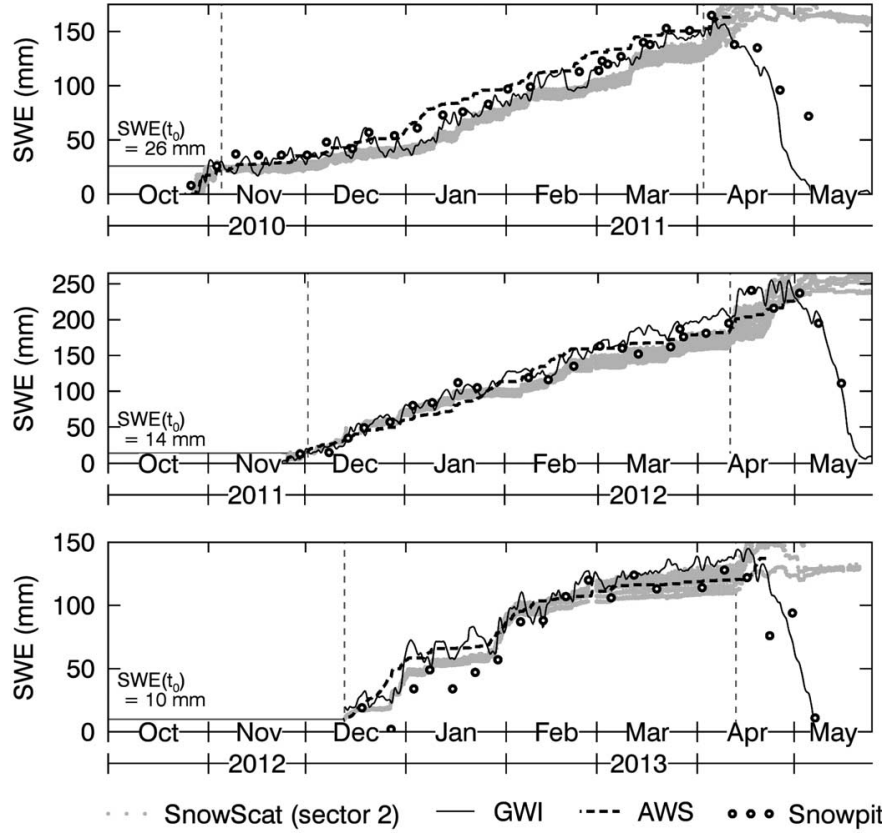

Fig. 13. SWE derived for sector 2 compared to measurements of the GWI, the AWS and the snow pit. Same processing settings as in Fig. $12\left(f_{1}=\right.$ $10.2 \mathrm{GHz}, f_{2}=12.5 \mathrm{GHz}$ ). Sector 2 is surrounded by trees, therefore, a few millimeter less SWE compared to sector 1 is expected. At December 12, 2012 (lowest panel), the sector was cleared from snow. $\operatorname{SWE}\left(t_{0}\right)$ was set to $10 \mathrm{~mm}$ instead of $0 \mathrm{~mm}$ for better visual comparison.

instrument due to a limited penetration depth. After the onset of snow melt in early April, the time series show unreliable results, again due to a very limited penetration depth. Compared to sector 1 , sector 2 was covered with about $20 \mathrm{~mm}$ less SWE (Fig. 13). As sector 2 is located between trees, some precipitation was presumably screened by surrounding trees. In the last season of the experiment, sector 2 was manually cleaned from snow on December 12, 2012. For a better visual comparison, $\mathrm{SWE}(t)$ was, therefore, set to $10 \mathrm{~mm}$ for all instruments in December when the snow was removed (lower panel of Fig. 13).

Systematic deviations were found between $\operatorname{SWE}(t)$ obtained from the SSI and SWE obtained from the AWS (dashed black line in Figs. 12 and 13). While the AWS precipitation data deviates significantly (up to $40 \mathrm{~mm}$ ) from the SSI data on time scales longer than weeks, the short-term signal of the AWS increases quite parallel to the SSI data. In contrast to the AWS, SWE $(t)$ follows accurately the long-term trend of the GWI signal, which is unfortunately quite noisy on timescales below weeks (max. deviation up to $\pm 30 \mathrm{~mm}$ SWE). As the AWS is located about $500 \mathrm{~m}$ north of the SSI, the systematic deviations can be partly attributed to spatially varying precipitation.

In a more quantitative comparison, SWE values determined at $10.2 \mathrm{GHz}$ for all subsectors of sector 1 were correlated with SWE values determined from AWS and GWI data during dry snow periods (Fig. 14, upper left and right). As already observed in the time-series, the GWI data are more noisy, whereas the AWS shows systematic deviations. To benefit from both the accurate short-term measurements of the AWS and from the long term stability of the GWI, a synthetic reference $\mathrm{SWE}_{\mathrm{REF}}$ was calculated by combining the
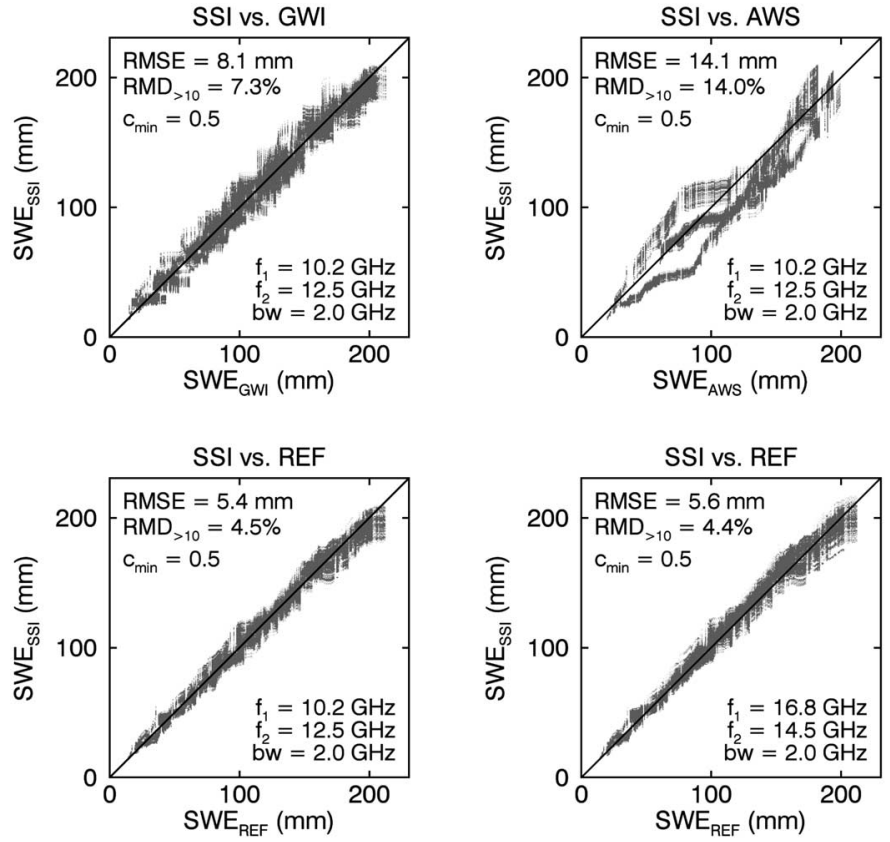

Fig. 14. SWE derived from SSI using a dual-frequency approach compared with three different validation data sets. Upper left: SSI versus SWE derived from the GWI by nuclear absorption measurements; upper right: SSI versus accumulated precipitation from the AWS; lower left: SSI versus SWE calculated from a synthetic reference REF, which combined the AWS and GWI data spectrally; lower right: SSI operating at $16.8 \mathrm{GHz}(+14.5 \mathrm{GHz})$ versus SWE from the synthetic reference REF.

low-frequency spectrum of the GWI (low-pass filtered, time constant $\tau>14$ days) and the high-frequency spectrum of the AWS (high-pass filtered, time constant $\tau<14$ days). SWE $\mathrm{REF}$ correlates significantly better with $\mathrm{SWE}_{\mathrm{SSI}}$ [Fig. 14(lower left)]. Compared to the GWI or AWS data, the RMSE is reduced from 8.1 and 14.1 to $5.4 \mathrm{~mm}$.

The relative mean deviation (RMD), which is a measure for the relative accuracy of the method, is given by

$$
\operatorname{RMD}_{\text {SWEmin }}=\operatorname{mean}\left(\frac{\left|\mathrm{SWE}_{\mathrm{SSI}}-\mathrm{SWE}_{\text {instr. }}\right|}{1 / 2\left(\mathrm{SWE}_{\mathrm{SSI}}+\mathrm{SWE}_{\text {instr. }}\right)}\right)
$$

and was calculated for each validation instrument instr. $\epsilon$ $\{$ AWS, GWI, REF $\}$ and for $\mathrm{SWE}>\mathrm{SWE}_{\min }=10 \mathrm{~mm}$. For SWE between 10 and $220 \mathrm{~mm}$, an RMD of only $4.5 \%$ was found when the SSI data were compared with the synthetic reference.

When increasing the frequency to $16.8 \mathrm{GHz}$ (plus $14.5 \mathrm{GHz}$ to recover lost phase cycles) neither the RMSE nor the RMD change significantly [Fig. 14(lower right)]. The fact that the results at $10.2 \mathrm{GHz}$ are almost identical to the results computed at $16.8 \mathrm{GHz}$ shows that the method works for $\mathrm{X}$ - and even for $\mathrm{Ku}$-band radar systems and that volume scattering for the dry taiga snow found at the test site can still be neglected at frequencies up to $16.8 \mathrm{GHz}$.

\section{B. Two-Frequency Extension}

The multifrequency approach of Section IV-E improves the computation of $\triangle \mathrm{SWE}$ significantly. During heavy snowfall, the phase difference measured by the SSI exceeded $\pm \pi$ within 

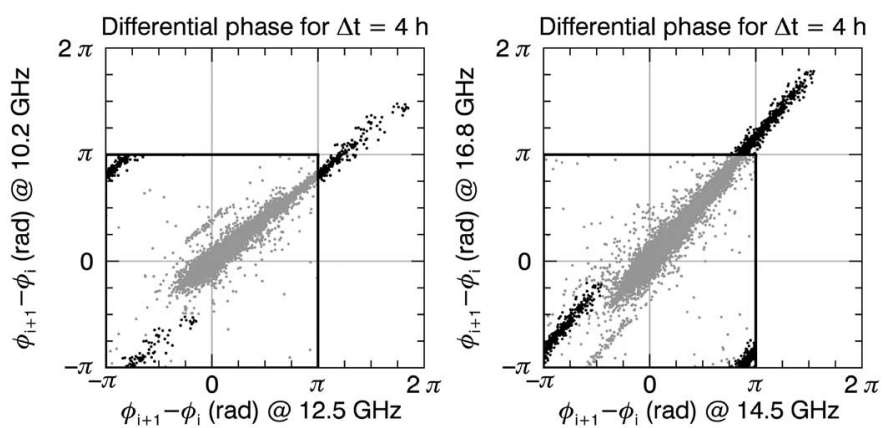

Fig. 15. Differential phase values $\phi_{i+1}-\phi_{i}$ which exceed $\pm \pi$ and "wrap around" are indicated as black dots. Left: at $10.2 \mathrm{GHz}$, only a few phase wraps occur. Right: at $16.8 \mathrm{GHz}$, a significant part of phase values are larger than $\pm \pi$, so that a two-frequency approach is required to derive the correct differential phase.
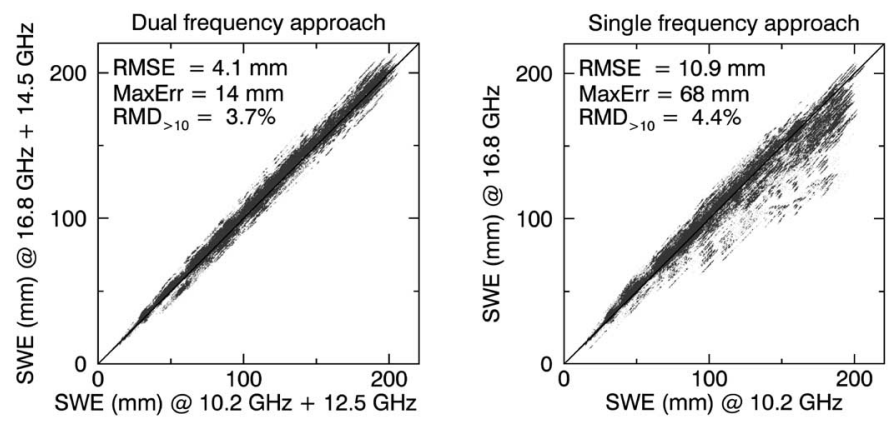

Fig. 16. Left: SWE obtained at two different frequencies $(10.2$ and $16.8 \mathrm{GHz})$ correlates with an RMSE of $4 \mathrm{~mm}$, when using the dual frequency approach. The excellent agreement indicates that volume scattering is still negligible at $16.8 \mathrm{GHz}$. Right: in the single frequency approach, phase wraps cause a significant underestimation of SWE at $16.8 \mathrm{GHz}$ compared to $10.2 \mathrm{GHz}$.

$4 \mathrm{~h}$ frequently. Fig. 15 shows scatter plots of measured phase differences $\phi_{i+1}-\phi_{i}$ for the two frequency pairs used to compute $\Delta \operatorname{SWE}(t)$. Phase differences, which did not require the reconstruction of lost phase cycles, are shown as gray dots between $\pm \pi$ (inside the black squares of Fig. 15). Black dots between $\pm \pi$ (inside the square) represent phase differences, for which phase cycles were lost. These phase differences were identified and unwrapped by solving (11). Not more than one phase cycle was lost for any phase difference. The unwrapped phase differences are shown as black dots outside of the square in Fig. 15. While at $10.2 \mathrm{GHz}$ only a few phase differences exceeded $\pi$ [Fig. 15(left)], already a significant fraction of the phase differences measured at $16.8 \mathrm{GHz}$ required unwrapping [Fig. 15(right)].

A direct comparison of the dual- and single-frequency approach is shown in Fig. 16. In contrast to the dual-frequency method where $\operatorname{SWE}(t)$ agrees within $4 \mathrm{~mm}$ RMSE (and a maximum error of $14 \mathrm{~mm}$ ), Fig. 16(left), phase wraps cause a significant underestimation at $16.8 \mathrm{GHz}$ in the single frequency approach where the RMSE increases to $11 \mathrm{~mm}$ (and the maximum error to $68 \mathrm{~mm}$ ), Fig. 16(right). The direct comparison of the results for both frequencies confirms the conclusion of the previous section that volume scattering is still largely negligible at $16.8 \mathrm{GHz}$, at least for the typical taiga snow pack observed in Sodankylä. The agreeing results show that the scattering center was located at the snow-ground interface for both frequencies.
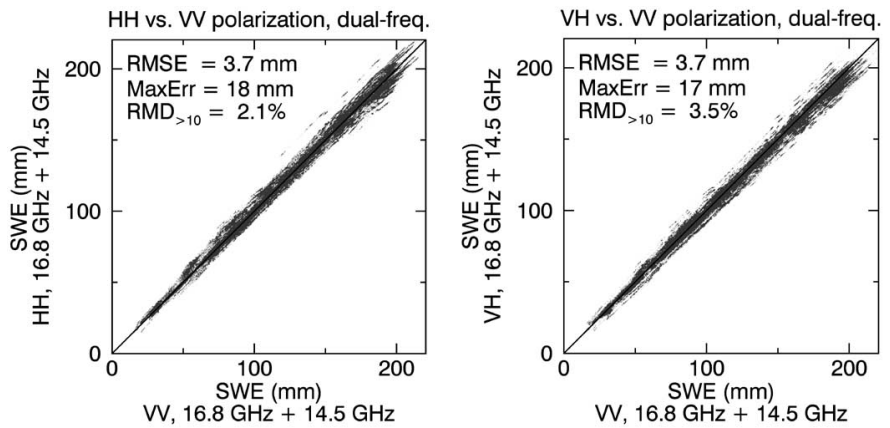

Fig. 17. Correlation of SWE computed for different polarizations at $16.8 \mathrm{GHz}$ with the dual-frequency approach $(16.8+14.5 \mathrm{GHz})$. Left: the results at VV and $\mathrm{HH}$ polarization agree within $3.7 \mathrm{~mm}$ RMSE. Right: at cross-pol (VH), SWE is minimally underestimated by $2 \%$ compared to VV.

\section{Polarization Dependence}

The agreement between validation data and SWE derived by differential interferometry (Fig. 14) is a strong indication that volume scattering is minimal at 10 and even at $16 \mathrm{GHz}$. For volume scattering, a polarization-dependent scattering center was suggested which is located above the ground [57]. If the scattering-center of one of the polarizations $\mathrm{VV}, \mathrm{HH}$, or $\mathrm{VH}$ were not at the snow-ground interface, the integrated phase difference and consequently the estimated SWE would be polarization dependent. In our analysis, no difference in SWE was found between $\mathrm{VV}$ and $\mathrm{HH}$ polarization [Fig. 17(left)]. Compared to VV, $2 \%$ less SWE were derived for the VH polarization [Fig. 17(right)]. The difference of 2\% was found for all four combinations of ( VV and $\mathrm{HH}$ ) with (VH and $\mathrm{HV}$ ). No frequency dependence was found and SWE derived from the $\mathrm{VH}$ polarization was also $2 \%$ lower at $10.2 \mathrm{GHz}$.

Large crystals of depth hoar at the snow-soil interface might be an explanation for the observed difference. Polarimetric phase differences $\phi_{\mathrm{VV}}-\phi_{\mathrm{HH}}$ of a few degree which were found to be proportional to the depth of fresh fallen snow [58], are too small to have an influence on SWE estimation, as phase difference of up to 240 radians were measured in this paper. The observation that the scattering center is the snow-ground interface for every polarization, agrees with the previous conclusion that volume scattering of dry snow can still be neglected at $16 \mathrm{GHz}$.

\section{Comparison of SWE with Laser Scans}

Despite the fact that SD does not necessarily correlate with SWE, SD derived from a terrestrial laser scanner (TLS) was compared with SWE computed from the SSI. The SD difference $\triangle \mathrm{SD}$ was computed from differencing elevation models measured by the TLS at two different times. The SWE difference $(\Delta \mathrm{SWE})$ was determined by integrating phase differences, starting from the time of the first TLS acquisition until the acquisition date of the second one. For cases, when the first snow fall occurred after the first acquisition, integration was started just before the first snow accumulated to avoid phase noise originating from wet soil or melting snow.

As expected, $\triangle \mathrm{SWE}$ correlates very weakly with $\triangle \mathrm{SD}$ (scatter plots in Fig. 18). Nevertheless, some patterns still match in 

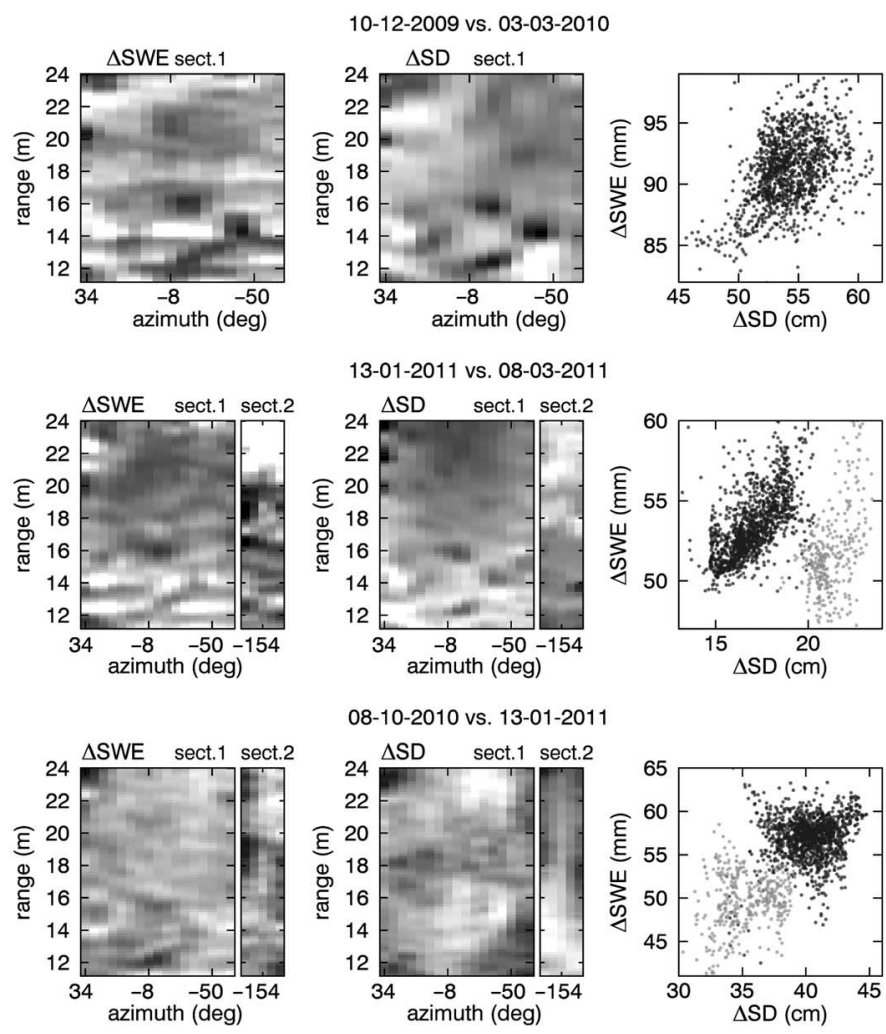

08-10-2010 vs. 13-01-2011
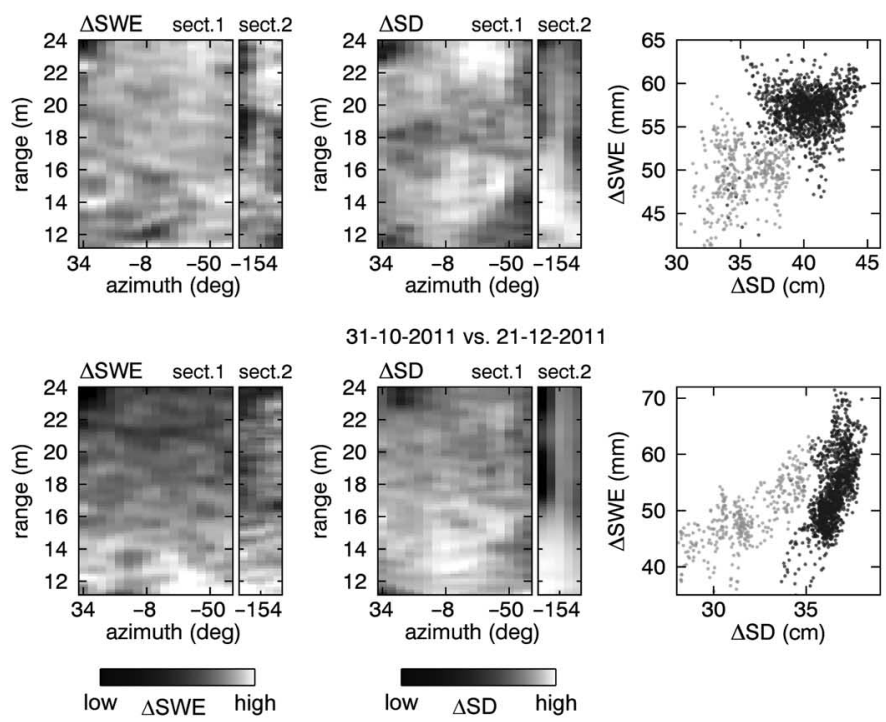

Fig. 18. SD difference $\Delta \mathrm{SD}$ compared with $\Delta \mathrm{SWE}$ from the SSI. The dates of the laser scanner acquisitions, from which $\Delta \mathrm{SD}$ was obtained, are given above the plots. First column: difference $\triangle \mathrm{SWE}$ in radar coordinates. Second column: $\Delta \mathrm{SD}$, converted into radar coordinates. Third column: scatter plots of $\Delta \mathrm{SWE}$ versus $\Delta \mathrm{SD}$. For the three lower rows, SnowScat data for both sectors, 1 and 2 , were available. The scatter plots contain data from both sectors: sector 1 (black dots) and sector 2 (gray dots).

the 2-D-plots for $\Delta \mathrm{SWE}$ and $\Delta \mathrm{SD}$, which are shown in the first and second column of Fig. 18.

In the first row, the correlation is very weak. Snow temperatures were well below zero, so that $\triangle \mathrm{SWE}$ was not affected by a limited penetration. However, $\Delta \mathrm{SD}$ was affected by snow settling during the time of almost three months between the acquisitions which reduced the correlation.

In the second row, the correlation over two months time difference seems to be higher. However, a large difference was found between the two sectors. On sector 1, From January to March 2011, 5-cm less snow accumulated but $\Delta$ SWE was a few millimeter higher compared to sector 2 (second scatter plot in Fig. 18). Lower values of $\Delta \mathrm{SD}$ in the far-range of sector 1 suggest a stronger snow settling compared to the near-range, which can be understood by a longer sun exposition. Air temperatures barely below zero and webcam images support this assumption.

For the third and fourth row of Fig. 18, $\Delta$ SWE was affected by wet snow in October 2010 and November 2011 and SWE retrieval was not very reliable due to a very low coherence. Nevertheless, a weak correlation was found between October 2011 and December 2011 (last row). For the last two rows of Fig. 18, $\Delta \mathrm{SD}$ and $\Delta \mathrm{SWE}$ were $5 \mathrm{~cm}$ and $10 \mathrm{~mm}$ smaller for sector 2 , probably due to surrounding trees which absorbed some precipitation.

The low correlation shows that no direct relation between SD and SWE exists, even on very small spatial scales of a few meter. Especially during winter, the comparison of height information does not correspond to $\triangle \mathrm{SWE}$ as snow settling causes a change in snow height, even when SWE does not change.

\section{E. Temporal Decorrelation of Multipass Coherence}

Temporal decorrelation and wet snow are the main limiting factors for a successful determination and integration of differential phases. In this section, time series of the multipass coherence $\gamma[S(t), S(t-\Delta t)]$ between two consecutive acquisitions with a temporal difference of $\Delta t=4 \mathrm{~h}$ are discussed with respect to meteorological conditions, especially snow drift. The time series of coherence are shown in Fig. 19 together with the meteorological data of four winter seasons.

During periods of dry snow (limited by the vertical dashed lines in Fig. 19), the magnitude of the coherence remained very high $|\gamma|>0.994$. As the dry snow was still transparent at $10-16 \mathrm{GHz}$, the coherence was primarily determined by soil properties. Soil temperature but also soil moisture were quite constant, due to the temperature insulating effect of snow. Further, vegetation which was fixed within the snow volume could not move and did, therefore, not affect the coherence. After snow melt set in and air temperatures rose above zero, the coherence decayed within hours to values of $0.3-0.7$ and stayed low until all snow had melted. At the end of May, when the soil was snow free, $|\gamma|$ increased to values of $0.7-0.994$, but never reached values as high as during the dry snow period. During snow free conditions, soil moisture and vegetation affected by wind altered the scattering properties of soil, consequently the coherence was reduced.

While generally the coherence was very high in the dry-snow period, a few events still caused a significant coherence loss during winter. The most interesting event occurred during the night from March 2 to March 3, 2010. Within a few hours, the average coherence dropped continuously from 0.999 to 0.6 and increased afterward continuously to 0.999 again. The coherence did not decrease simultaneously for all subsectors, but dropped at patches with different range and azimuth values at different times. 15-20 mm SWE accumulated one day before the event. Wind gust up to $15 \mathrm{~m} / \mathrm{s}$ were observed by the AWS during the event. Pictures from a webcam which captured the test site every 15 min showed the development of sastrugi and confirmed significant snow drift. Similar events, where snow drift reduced the coherence happened at 27-01-2010, 02-012012, and 29-12-2012 (black arrows in Fig. 19). Almost no 

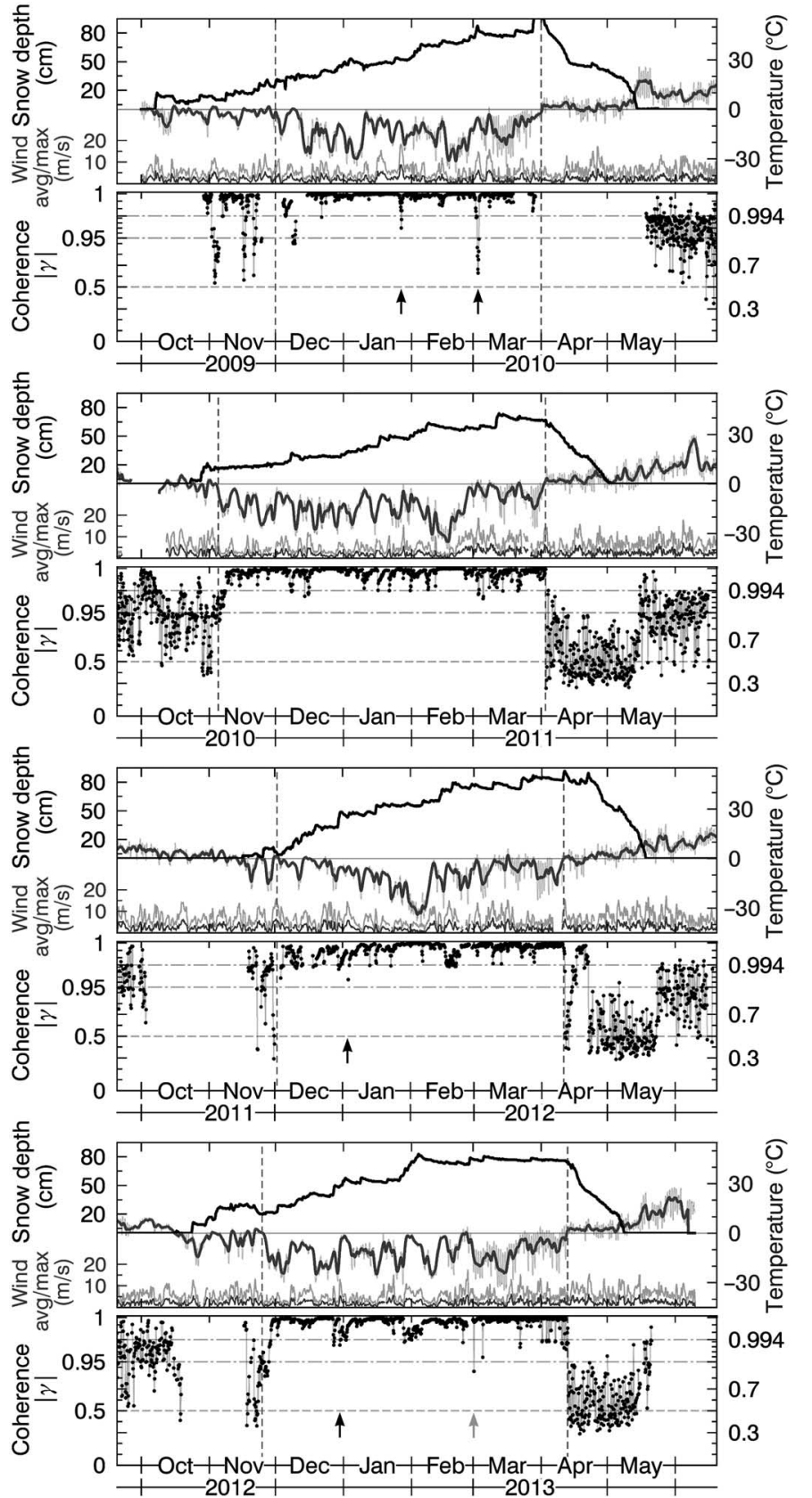

Fig. 19. Meteorological data and temporal coherence $(\Delta t=4 \mathrm{~h})$ of consecutive acquisitions (sector 1) during the four seasons of the experiment. Air temperature ( $2 \mathrm{~m}$ above ground), SD, the 6-h mean wind speed, and the 6-h maximum wind gust speed were measured by the AWS. Two vertical dashed lines delimit the dry snow period. The coherence magnitude $|\gamma|$ was calculated for $f=10.2 \mathrm{GHz}, b w=2 \mathrm{GHz}, \theta=30^{\circ}$, azimuth subsectors were averaged. To facilitate the identification of small coherence losses during the dry-snow period, the y-axis was piecewise linearly scaled. Horizontal break lines at $|\gamma|=0.994$ and 0.95 separate different linear scales. A third graydashed line indicates the coherence threshold of $|\gamma|=0.5$, which was used to determine $\operatorname{SWE}(t)$.

coherence loss was observed for dates with strong winds where the snow has settled already.

A man-made coherence reduction was observed at 01-032013 when a trench was dug into sector 1 (gray arrow in Fig. 19). The trench was visible as a very local coherence loss
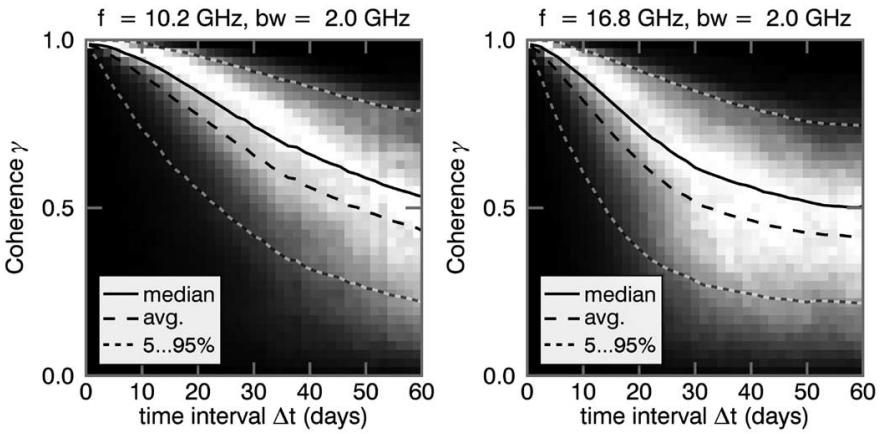

Fig. 20. Coherence decay shown as 2-D histogram for a temporal baseline $\Delta t$ from 0 to 60 days between two acquisitions. The coherence decay is shown for $10.2 \mathrm{GHz}$ (left) and $16.8 \mathrm{GHz}$ (right). All acquisitions were coregistered to compensate range-shifts due to a snow related signal delay.

in the near range of the instrument. Heavy snow fall without wind drift reduced also the coherence, as an increasing signal delay caused small shifts between acquisitions leading to a weak misregistration of consecutive scenes. Wet snow falling ontop of dry snow caused a major coherence loss between 11-04-2012 and 16-04-2012. Interestingly, after subsequent refreezing the coherence recovered completely before snow melt finally set in end of April.

Compared to air- or space-borne acquisitions, it surprises that the coherence was very high during winter. While a strong coherence loss is known for wet snow [16], [17] we show that the coherence can be very high for dry snow, probably because all vegetation at the test site was covered and fixed by snow. For air- or space borne acquisitions the coherence will decay much faster also for dry snow as vegetation, which is protruding from the snow, will be moved slightly in its position due to weather conditions and the weight of snow and will therefore reduce the coherence.

\section{F. Decay of Multipass Coherence}

The large amount of acquisitions allowed us a detailed insight into how the coherence decayed in time. The coherence decay was analyzed for each of the three characteristic periods during the experiment: dry snow, snow melt, and no snow. Statistical properties of the coherence $\gamma(t, t-\Delta t)$ between two acquisitions separated by the time $\Delta t$ were determined. For each acquisition at time $t, \gamma$ was calculated for 50 randomly selected acquisitions with $\Delta t$ ranging between $4 \mathrm{~h}$ and 60 days. Several ten-thousands of acquisition pairs were evaluated for each of the three periods.

During the dry snow period, the coherence decayed almost linearly from 1 to 0.7 within 20 to 30 days and decayed faster for higher frequencies (Fig. 20). As already observed in the previous section, the coherence during snow melt was very low [mean between 0.25 and 0.4, Fig. 21(left)], and decayed faster than the shortest time interval $(4 \mathrm{~h})$ between two consecutive acquisitions. As shown in Fig. 21(right) for snow free conditions, the coherence decayed within 5 to 7 days below 0.7, but stayed significantly higher (mean between 0.4 and 0.6 ) compared to snow melt. Because vegetation could move during 

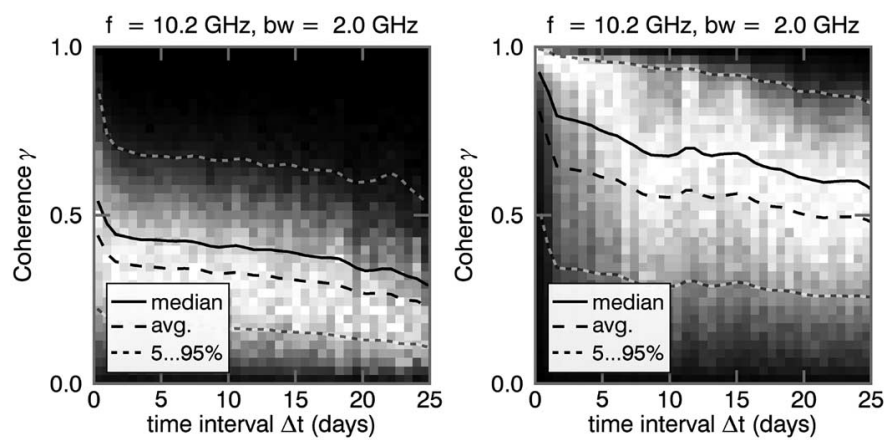

Fig. 21. Coherence decay during snow melt (left) and snow free conditions (right) at $10.2 \mathrm{GHz}$ for $\Delta t$ between 0 and 25 days. During snow melt, the coherence decayed within less than $4 \mathrm{~h}$ (mid. April-mid. May) to values below 0.5 . In the summer season, the coherence shows a large variety of values but is generally lower compared to dry snow conditions (Fig. 20).

snow free conditions, the coherence was lower compared to dry snow conditions.

\section{CONCLUSION}

We developed a method to derive $\triangle \mathrm{SWE}$ from time series of differential interferograms and extended the SWE dependent phase delay, originally calculated by [15] to all realistic densities of snow and also to inhomogeneous, layered snow packs. A sensitivity analysis with respect to snow density and incidence angle showed a very weak dependence on snow density. Phase wraps, which occurred due to heavy snow accumulation between two acquisitions, were reconstructed with a two-frequency approach.

The method was successfully demonstrated by determining $\triangle \mathrm{SWE}$ up to $200 \mathrm{~mm}$ from radar acquisitions of the SSI at frequencies between 10 and $16 \mathrm{GHz}$. The data was obtained from dry taiga snow in northern Finland. The results agree within an RMSE of \pm 5 to $15 \mathrm{~mm}$ SWE with validation measurements, depending on which validation data set/instrument was used.

Results obtained at $10 \mathrm{GHz}$ agree within $4 \mathrm{~mm}$ SWE with results at $16 \mathrm{GHz}$. The agreement between both frequencies is a strong indication that volume scattering in dry taiga-type snow, as it was present at the test site, can still be neglected at $16 \mathrm{GHz}$. SWE data determined at different polarizations agreed within $2 \%-3 \%$ and support the observation that the main scattering center is located at the soil-snow interface.

The coherence decay was analyzed in detail. During periods of dry snow, a very high coherence was maintained which decayed within 20-30 days. For wet snow, the coherence decayed in less than $4 \mathrm{~h}$. For dry snow, the coherence was exceptionally stable, as all vegetation was covered by the snow volume and was not affected by weather. When considering air- or space-borne SAR acquisitions, vegetation above the snow will cause decorrelation, as the load of snow on vegetation will quickly change with meteorological conditions, causing a fast rearrangement of scatterers, resulting in a fast coherence decay. Consequently, the method, which relies on differential interferograms, is better suited to regions with low vegetation covered by snow.
With our method applied at frequencies above $10 \mathrm{GHz}$, we showed that large $\Delta$ SWE of dry snow can be accurately determined for regions with long periods of cold temperatures. The method might also be suitable for regions with partially wet snow like alpine regions, when lower frequencies are used which can penetrate wet snow and which are less sensitive to temporal decorrelation and phase wrapping. A radar system with a high repeat time operating at low frequencies might be best suited for the proposed method. At lower frequencies, it might even be possible to determine the total SWE $(t)$ including the first layer of wet early winter snow. The optimal frequency has to be determined by a tradeoff between high accuracy from short wavelengths and an increasing robustness at low frequencies with respect to penetration into wet snow and loss of coherence. Using snow free reference points on the ground and fast repeat cycles, future space-borne SAR sensors should be able to use the proposed method to determine $\mathrm{SWE}(t)$.

\section{ACKNOWLEDGMENT}

The staff at FMI-ARC and the WSL Institute for Snow and Avalanche Research SLF are acknowledged for the collection of in situ data. The Finnish Geodetic Institute FGI is acknowledged for providing the terrestrial laser scanner data. Thanks to C. Mätzler for his valuable inputs to the dielectric properties of snow and the members of the HGF Alliance HA-310 for vivid discussions. We highly appreciate the anonymous reviewer for pointing out that SWE, expressed in $\mathrm{mm}$, requires normalization by the density of water, which is missing in many publications.

\section{REFERENCES}

[1] J. Lemmetyinen et al., "Technical assistance for the deployment of an X- to Ku-band scatterometer during the NoSREx-III experiment," ESA ESTEC, Noordwijk, Final report, ESA ESTEC Contract No. 22671/09/NL/JA/ef, Tech. Rep., 2013.

[2] M. Takala et al., "Estimating northern hemisphere snow water equivalent for climate research through assimilation of space-borne radiometer data and ground-based measurements," Remote Sens. Environ., vol. 115, no. 12, pp. 3517-3529, 2011.

[3] E. Brun et al., "Simulation of northern Eurasian local snow depth, mass, and density using a detailed snowpack model and meteorological reanalyses," J. Hydrometeor, vol. 14, no. 1, pp. 203-219, 2013.

[4] D. Archer and D. Stewart, "The installation and use of a snow pillow to monitor snow water equivalent," Water Environ. J., vol. 9, no. 3, pp. 221230, 1995.

[5] J.-P. Martin, A. Houdayer, C. Lebel, Y. Choquette, P. Lavigne, and P. Ducharme, "An unattended gamma monitor for the determination of snow water equivalent (SWE) using the natural ground gamma radiation," in Proc. IEEE Nucl. Sci. Symp. Conf. Rec. (NSS'08), 2008, pp. 983-988.

[6] N. Kinar and J. Pomeroy, "Automated determination of snow water equivalent by acoustic reflectometry," IEEE Trans. Geosci. Remote Sens., vol. 47, no. 9, pp. 3161-3167, Sep. 2009.

[7] M. V. Nikiforov, N. N. Pegoev, and A. N. Stroganov, "Aerial gamma survey of snow cover and soil moisture," Hydrol. Sci. Bull. Sci. Hydrolog., vol. 25, pp. 85-91, 1980.

[8] R. Grasty, "Direct snow-water equivalent measurement by air-borne gamma-ray spectrometry," J. Hydrol., vol. 55, no. 1-4, pp. 213-235, 1982.

[9] D. Cline et al., "Overview of the NASA cold land processes field experiment (CLPX-2002)," Proc. SPIE, vol. 4894, p. 361, 2003.

[10] D. Cline and T. Carrol, CLPX-Airborne Gamma Snow and Soil Moisture Surveys. Boulder, CO, USA: NASA DAAC, National Snow and Ice Data Center, 2005. 
[11] C. Derksen, A. Walker, and B. Goodison, "A comparison of 18 winter seasons of in situ and passive microwave-derived snow water equivalent estimates in Western Canada," Remote Sens. Environ., vol. 88, no. 3, pp. 271-282, 2003.

[12] R. Kelly, A. Chang, L. Tsang, and J. Foster, "A prototype AMSR-E global snow area and snow depth algorithm," IEEE Trans. Geosci. Remote Sens., vol. 41, no. 2, pp. 230-242, Feb. 2003.

[13] A. K. Gabriel, R. M. Goldstein, and H. A. Zebker, "Mapping small elevation changes over large areas: Differential radar interferometry," $J$. Geophys. Res., vol. 94, no. B7, pp. 9183-9191, 1989.

[14] H. A. Zebker, P. A. Rosen, R. M. Goldstein, A. Gabriel, and C. L. Werner, "On the derivation of coseismic displacement fields using differential radar interferometry: The Landers earthquake," J. Geophys. Res. Solid Earth, vol. 99, no. B10, pp. 19 617-19 634, 1994.

[15] T. Guneriussen, K. A. Høgda, H. Johnsen, and I. Lauknes, "InSAR for estimation of changes in snow water equivalent of dry snow," IEEE Trans. Geosci. Remote Sens., vol. 39, no. 10, pp. 2101-2108, Oct. 2001.

[16] J. Shi, S. Hensley, and J. Dozier, "Mapping snow cover with repeat pass synthetic aperture radar," in Proc. IEEE Int. Geosci. Remote Sens. Symp. (IGARSS'97), Aug. 1997, vol. 2, pp. 628-630.

[17] G. Singh, G. Venkataraman, Y. S. Rao, and V. Kumar, and Snehmani, "InSAR coherence measurement techniques for snow cover mapping in Himalayan region," in Proc. IEEE Int. Geosci. Remote Sens. Symp. (IGARSS'08), 2008, vol. 4, pp. 1077-1080.

[18] Z. Wang and S. Li, "Detection of winter frost heaving of the active layer of Arctic permafrost using SAR differential interferograms," in Proc. IEEE Int. Geosci. Remote Sens. Symp. (IGARSS'99), 1999, vol. 4, pp. 19461948.

[19] H. A. Zebker, P. A. Rosen, and S. Hensley, "Atmospheric effects in interferometric synthetic aperture radar surface deformation and topographic maps," J. Geophys. Res. Solid Earth, vol. 102, no. B4, pp. 7547-7563, 1997.

[20] K. Sarabandi and R. Azadegan, "Simulation of interferometric SAR response to rough surfaces covered with a dielectric layer," in Proc. IEEE Int. Geosci. Remote Sens. Symp. (IGARSS'00), 2000, vol. 4, pp. 1739-1741.

[21] H. Rott, T. Nagler, and R. Scheiber, "Snow mass retrieval by means of SAR interferometry," in Proc. 3rd Fringe Workshop Eur. Space Agency Earth Observ., 2003.

[22] S. Li and M. Sturm, "Patterns of wind-drifted snow on the Alaskan arctic slope, detected with ERS-1 interferometric SAR," J. Glaciol., vol. 48, no. 163 , pp. 495-504, 2002.

[23] E. J. Deeb, R. R. Forster, and D. L. Kane, "Monitoring snowpack evolution using interferometric synthetic aperture radar on the North Slope of Alaska," Int. J. Remote Sens., vol. 32, no. 14, pp. 3985-4003, 2011.

[24] G. Engen, T. Guneriussen, and Y. Overrein, "Delta-K interferometric SAR technique for snow water equivalent (SWE) retrieval," IEEE Geosci. Remote Sens. Lett., vol. 1, no. 2, pp. 57-61, Apr. 2004.

[25] Y. Larsen, E. Malnes, and G. Engen, "Retrieval of snow water equivalent with envisat ASAR in a Norwegian hydropower catchment," in Proc. IEEE Int. Geosci. Remote Sens. Symp. (IGARSS'05), Jul. 2005, vol. 8 , pp. 5444-5447.

[26] P. Berardino, G. Fornaro, R. Lanari, and E. Sansosti, "A new algorithm for surface deformation monitoring based on small baseline differential SAR interferograms," IEEE Trans. Geosci. Remote Sens., vol. 40, no. 11, pp. 2375-2383, Nov. 2002.

[27] S.-H. Hong, S. Wdowinski, S.-W. Kim, and J.-S. Won, "Multi-temporal monitoring of wetland water levels in the Florida Everglades using interferometric synthetic aperture radar (InSAR)," Remote Sens. Environ., vol. 114, no. 11, pp. 2436-2447, 2010.

[28] S.-H. Hong and S. Wdowinski, "Multitemporal multitrack monitoring of wetland water levels in the Florida Everglades using ALOS PALSAR data with interferometric processing," IEEE Geosci. Remote Sens. Lett., vol. 11, no. 8, pp. 1355-1359, Aug. 2014.

[29] G. Luzi, M. Pieraccini, L. Noferini, D. Mecatti, G. Macaluso, and C. Atzeni, "Ground-based microwave interferometric measurements over a snow covered slope: An experimental data collection in Tyrol (Austria)," in Proc. IEEE Int. Geosci. Remote Sens. Symp. (IGARSS'07), Jul. 2007, pp. $1452-1455$.

[30] H. Rott et al., "CoreH2O: Cold regions hydrology high-resolution observatory for snow and cold land processes," Proc. IEEE, vol. 98, no. 5, pp. 752-765, May 2010.

[31] C. Werner, A. Wiesmann, T. Strozzi, M. Schneebeli, and C. Mätzler, "The SnowScat ground-based polarimetric scatterometer: Calibration and initial measurements from Davos Switzerland," in Proc. IEEE Int. Geosci. Remote Sens. Symp. (IGARSS'10), Jul. 2010, pp. 2363-2366.
[32] A. Wiesmann, C. Werner, and T. Strozzi, "SnowScat, X- to Ku-band scatterometer development," in Proc. ESA Living Planet Symp., Bergen, Norway, Jun. 28/Jul. 2, 2010.

[33] R. Bamler and P. Hartl, "Synthetic aperture radar interferometry," Inverse Prob., vol. 14, pp. R1-R54, 1998.

[34] G. Krieger et al., "Tandem-L: And innovative interferometric and polarimetric SAR mission to monitor earth system dynamics with high resolution," in Proc. IEEE Int. Geosci. Remote Sens. Symp. (IGARSS), Jul. 2010, pp. 253-256.

[35] S. N. Madsen, "Absolute phase determination techniques in SAR interferometry," Proc. SPIE, vol. 2487, pp. 393-401, 1995.

[36] N. Veneziani, F. Bovenga, and A. Refice, "A wide-band approach to the absolute phase retrieval in SAR interferometry," Multidimension. Syst. Signal Process., vol. 14, no. 1-3, pp. 183-205, 2003.

[37] A. Sihvola, "Mixing rules with complex dielectric coefficients," Subsurface Sens. Technol. Appl., vol. 1, no. 4, pp. 393-415, 2000.

[38] G. P. Johari, "The dielectric properties of $\mathrm{H}_{2} \mathrm{O}$ and $\mathrm{D}_{2} \mathrm{O}$ ice $\mathrm{Ih}$ at $\mathrm{MHz}$ frequencies," J. Chem. Phys., vol. 64, no. 10, pp. 3998-4005, 1976.

[39] P. Bohleber, N. Wagner, and O. Eisen, "Permittivity of ice at radio frequencies: Part II. Artificial and natural polycrystalline ice," Cold Reg. Sci. Technol., vol. 83-84, pp. 13-19, 2012.

[40] S. G. Warren, "Optical constants of ice from the ultraviolet to the microwave," Appl. Opt., vol. 23, no. 8, pp. 1206-1225, Apr. 1984.

[41] S. G. Warren and R. E. Brandt, "Optical constants of ice from the ultraviolet to the microwave: A revised compilation," J. Geophys. Res. Atmos., vol. 113, no. D14, pp. 1-10, 2008.

[42] C. Mätzler, "Microwave permittivity of dry snow," IEEE Trans. Geosci. Remote Sens., vol. 34, no. 2, pp. 573-581, Mar. 1996.

[43] A. Wiesmann and C. Mätzler, "Microwave emission model of layered snowpacks," Remote Sens. Environ., vol. 70, no. 3, pp. 307-316, 1999.

[44] C. Mätzler, "Relation between grain-size and correlation length of snow," J. Glaciol., vol. 48, no. 162, pp. 461-466, 2002.

[45] C. Mätzler and A. Wiesmann, "Extension of the microwave emission model of layered snowpacks to coarse-grained snow," Remote Sens. Environ., vol. 70, no. 3, pp. 317-325, 1999.

[46] A. Judson and N. Doesken, "Density of freshly fallen snow in the central Rocky Mountains," Bull. Amer. Meteorol. Soc., vol. 81, no. 7, pp. 15771587, 2000.

[47] P. J. Roebber, S. L. Bruening, D. M. Schultz, and J. V. Cortinas, "Improving snowfall forecasting by diagnosing snow density," Weather Forecasting, vol. 18, no. 2, pp. 264-287, 2003.

[48] K. J. Bormann, S. Westra, J. P. Evans, and M. F. McCabe, "Spatial and temporal variability in seasonal snow density," J. Hydrol., vol. 484, pp. 63-73, 2013.

[49] M. Sturm, B. Taras, G. E. Liston, C. Derksen, T. Jonas, and J. Lea, "Estimating snow water equivalent using snow depth data and climate classes," J. Hydrometeorol., vol. 11, no. 6, pp. 1380-1394, 2010.

[50] S. Rasmus, "Spatial and temporal variability of snow bulk density and seasonal snow densification behavior in Finland," Geophysica, vol. 49, pp. 53-74, 2013.

[51] P. Bartelt and M. Lehning, "A physical SNOWPACK model for the Swiss avalanche warning: Part I: Numerical model," Cold Regions Sci. Technol., vol. 35, no. 3, pp. 123-145, 2002.

[52] D. L. Anderson and C. S. Benson, The Densification and Diagenesis of Snow. In: Ice and Snow: Properties, Processes and Applications. Cambridge, MA, USA: MIT Press, 1963.

[53] M. Spencer, R. Alley, and T. Creyts, "Preliminary firn-densification model with 38-site dataset," J. Glaciol., vol. 47, no. 159, pp. 671-676, 2001.

[54] L. Jun and H. J. Zwally, "Modeled seasonal variations of firn density induced by steady-state surface air-temperature cycle," Ann. Glaciol., vol. 34, no. 1, pp. 299-302, 2002.

[55] M. Sturm and C. Benson, "Scales of spatial heterogeneity for perennial and seasonal snow layers," Ann. Glaciol., vol. 38, no. 1, pp. 253-260, 2004.

[56] S. Sugiyama et al., "Snow density along the route traversed by the Japanese-Swedish Antarctic expedition 2007/08," J. Glaciol., vol. 58, no. 209, pp. 529-539, May 2012.

[57] K. P. Papathanassiou and S. R. Cloude, "Single-baseline polarimetric SAR interferometry," IEEE Trans. Geosci. Remote Sens., vol. 39, no. 11, pp. 2352-2363, Nov. 2001.

[58] S. Leinss, G. Parrella, and I. Hajnsek, "Snow height determination by polarimetric phase differences in X-band SAR data," IEEE J. Sel. Topics Appl. Earth Observ. Remote Sens., vol. 7, no. 9, pp. 3794-3810, Sep. 2014. 


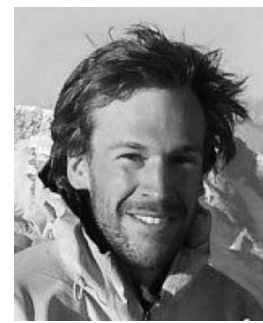

Silvan Leinss (S'12) received the Dipl. degree in physics from the University of Constance, Konstanz, Germany, in 2008

After working in the field of light scattering in colloidal random media at the University of Constance, Konstanz, Germany, and light scattering statistics in Bose-Einstein condensates at ETH Zürich, Zürich, Switzerland, he started in 2011 the Ph.D. in the field of radar remote sensing and specialized in polarimetric and interferometric approaches for the determination of snow properties. His research interests include electromagnetic scattering properties of ice and snow, radar interferometry, digital elevation models, and efficient implementations of processing algorithms.

Andreas Wiesmann (M'00-SM'06) received the Diploma degree in physics from the Institute of Applied Physics, University of Bern, Bern, Switzerland, in 1994, and the Ph.D. degree in physics from the same university in 1998.

Since 1998, he has been with GAMMA Remote Sensing AG, Gümligen, Switzerland. His research interests include the interaction of microwaves with natural targets, in particular snow, microwave hardware development, distributed high performance computing, large scale data processing, and computer security.

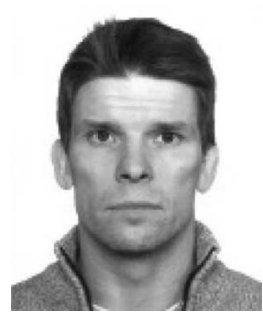

Juha Lemmetyinen received the D.Sc.(Tech.) degree in electrical engineering from Aalto University, Espoo, Finland, in 2012.

From 2004 to 2008, he was a researcher with the TKK Laboratory of Space Technology and the TKK Department of Radio Science and Engineering, where he specialized in radiometer calibration techniques and remote sensing. Since 2009, he has been a scientist with the Arctic Research Unit, Finnish Meteorological Institute, Helsinki, Finland. Since 2014, he has acted as the Head of the group for research on satellite observations and cryosphere processes. His research interests include applications of microwave radiometers and synthetic aperture radar in remote sensing of snow and soil.

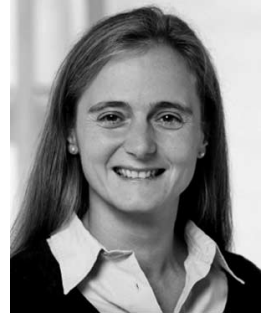

Irena Hajnsek (AM'01-M'06-SM'09-F'14) received the Dipl. degree (Hons.) from the Free University of Berlin, Berlin, Germany, and the Dr. degree (Hons.) from the Friedrich Schiller University of Jena, Jena, Germany, in 1996 and 2001, respectively.

She is a Professor of Earth Observation with the Institute of Environmental Engineering, Swiss Federal Institute of Technology (ETH) Zürich, Zürich, Switzerland, since November 2009, and at the same time, Head of the Polarimetric SAR Interferometry Research Group of the Microwave and Radar Institute at German Aerospace Center. Her research interests include electromagnetic propagation and scattering theory, radar polarimetry, SAR and interferometric SAR data processing techniques, and environmental parameter modeling and estimation.

Dr. Hajnsek has been the Science Coordinator of the German Satellite Mission TanDEM-X, since 2010. She was a Technical Program Co-Chair of the IEEE IGARSS 2012 Symposium in Munich. Since 2013 she is a member of the IEEE GRSS AdCom. 